\title{
Dinâmica do uso e ocupação do solo no litoral sul do estado do Espírito Santo, Brasil
}

\section{Land use and occupation dynamics of south littoral of Espírito Santo state, Brazil}

\author{
Gisele GIRARDI* \\ Renata de Souza COMETTI**
}

\begin{abstract}
RESUMO
Este artigo analisa alguns aspectos do uso de terra e da ocupação do litoral sul do estado do Espírito Santo, Brasil, região composta por onze municípios, cinco dos quais incluídos na região metropolitana da Grande Vitória. Justifica, inicialmente, o recorte territorial adotado e apresenta uma análise histórica desta ocupação, que é articulada ao movimento geral da organização do espaço no estado do Espírito Santo. Discute, com base em análises de tabelas, a dinâmica demográfica e urbana, os aspectos infra-estruturais e indicadores socioeconômicos. Finalmente, aponta algumas tendências e cenários futuros, com ênfase na recente exploração de petróleo no mar territorial sul-espiritossantense, força econômica que promove uma nova organização do espaço. Este trabalho resultou de pesquisa desenvolvida pela equipe Espírito Santo do Subgrupo Temático Uso e Ocupação do Grupo Temático Modelagem e Monitoramento da Erosão e Ocupação Costeira Instituto do Milênio (Milênio-Recos-MMOC), e pretende fornecer alguns elementos à compreensão das relações entre os elementos naturais e humanos que configuraram as zonas costeiras brasileiras.

Palavras-chave: uso e ocupação do solo; organização do espaço costeiro; litoral sul do Espírito Santo.
\end{abstract}

\begin{abstract}
This paper analyse some aspects of land use and occupation of the south littoral of Espírito Santo's state, Brazil, region composed by eleven municipalities, five of them included in Grande Vitória's metropolitan region. Justifies, initially, the territorial contour adopted and to present an historical approach of this occupation, that is articulated to the general movement of the space organization in Espírito Santo's state. Discusses, based in analyses of tables, the demographic and urban dynamics, infra-structurals aspects and social and economics indicators. Finally, points out some future tendencies
\end{abstract}

\footnotetext{
Professora Doutora no Departamento de Geografia do Centro de Ciências Humanas e Naturais da Universidade Federal do Espírito Santo e membro do Sub-Grupo Temático Uso e Ocupação do Solo do Instituto do Milênio - Recursos Costeiros - Grupo Temático Modelagem e monitoramento da erosão e ocupação costeira (MilênioRecos-MMOC).

** Aluna do Curso de Geografia da Universidade Federal do Espírito Santo e Bolsista de Iniciação Científica (CNPq) no Milênio-Recos-MMOC no período 2003/2004.
} 
and sceneries, with emphasis on recent off-shore oil exploration, economic force that promotes a new space organization. This paper is an result of the research developped by Espírito Santo's team of thematic sub-group "Land Use and Occupation", of thematic group "Modeling and Monitoring of the Coastal Erosion and Occupation" of the "Instituto do Milênio" (Milênio-Recos-MMOC), and intend to provide some elements to comprehension of relations between natural and human elements that configure the brazilians coastal zones.

Key-words: land use and occupation; space organization coastal; south littoral of Espírito Santo state.

\section{Introdução}

A dinâmica do uso e ocupação do solo do litoral sul do Espírito Santo inscreve-se no movimento geral da organização do espaço capixaba, ora como locus do desenvolvimento econômico, particularmente urbano e industrial, ora como área pressionada para atender demandas secundárias dessas atividades. Partiremos, portanto, de uma visão macro da dinâmica da ocupação do território capixaba para situar o litoral sul.

Inicialmente cabe apontar que denominaremos litoral sul do Espírito Santo o conjunto de municípios abrangidos pela faixa terrestre da zona costeira (em conformidade com o Plano Nacional de Gerenciamento Costeiro) entre Vitória e Presidente Kennedy (Figura 1). Essa divisão regional difere da divisão mesorregional do IBGE, pois abarca parcialmente os municípios da faixa terrestre da zona costeira da Região da Grande Vitória e a totalidade dos municípios da faixa terrestre da zona costeira das Regiões Central e Sul. Por outro lado, essa divisão aproxima-se dos setores 4 e 5 propostos por Martin et al. (1989), com base na análise do grau de desenvolvimento dos depósitos quaternários costeiros. As divisões citadas podem ser observadas na Figura 2.

\section{Visão geral da organização do território do Espí- rito Santo}

A despeito de ter áreas cuja ocupação data de 1535, é somente no século XX que o território do Espírito Santo se integra. A faixa hoje representada pelo estado do Espírito Santo caracterizava-se, na época do descobrimento, em termos naturais, pelo ecossistema de Mata Atlântica, e era habitada por nações indígenas. Segundo o naturalista Auguste de Saint-Hilaire (1883), essa situação, hostil ao colonizador português, desmotivou a ocupação das terras interiores do Espírito Santo, e o estado foi somente ocupa- do por fazendas, principalmente jesuítas, em trechos do litoral. No período subseqüente, já no ciclo mineiro, o território do Espírito Santo funcionou como "barreira natural" às Minas Gerais e essa condição se manteve até o século XIX.

O que tirou o Espírito Santo da situação de estagnação econômica foi o ciclo do café, ou, conforme Borgo et al. (1996), o "efeito-difusão" do café, que no final do século XIX atingiu primordialmente o sul do estado como expansão das áreas cafeicultoras do Rio de Janeiro e Minas Gerais.

Já na área serrana central, nesse período houve um grande fluxo de imigrantes, em sua maioria alemães e italianos, que intensificaram o plantio do café. A reprodução dessa população migrante foi o elemento primordial para expansão da área cafeicultora para as terras situadas ao norte do rio Doce, que mantinha, até então, sua situação natural praticamente inalterada.

O deslocamento da frente pioneira para o norte do rio Doce caracterizou-se, segundo Becker (1973), por três fases distintas. Entre 1928 e 1950 houve o rápido crescimento da atividade, motivado pela construção da ponte sobre o rio Doce em Colatina, pela alta do preço do café no mercado internacional após a crise de 1929 e pela crescente demanda por madeira para a expansão urbana e industrial do Sudeste. Entre 1950 e 1960, já com o esgotamento da madeira e com o preço do café em baixa no mercado internacional, o crescimento é lento. A partir de 1960 houve, por parte do governo estadual, uma intensa política de erradicação dos cafezais, que, somada à descapitalização dos proprietários rurais, resultou numa forte concentração fundiária no norte do estado com a implantação da atividade pecuária (de baixa produtividade), seguida da implantação de monoculturas de cana-de-açúcar e eucalipto, principalmente, para fornecimento de matéria-prima aos processos industriais que se instalam a partir dos anos 1970.

Nas regiões Vitória e Sul, no início do século XIX, houve intensificação das plantações de café, e na região de Vitória (área que hoje engloba os municípios de Vitória, 


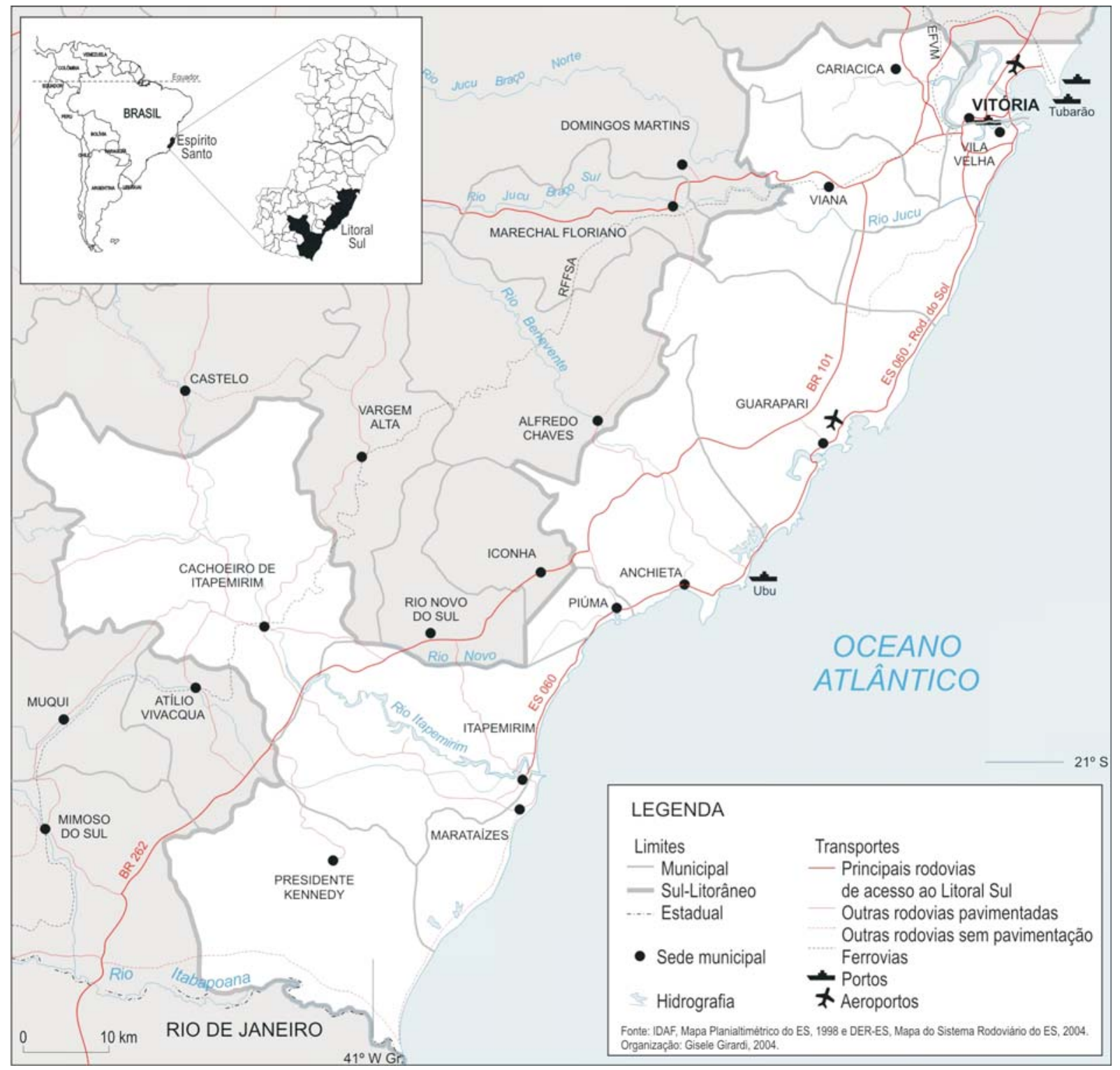

Serra, Cariacica, Viana, Vila Velha, Santa Leopoldina, Marechal Floriano e Domingos Martins) o café substituiu as antigas lavouras de subsistência. Já na região Sul, nos vales dos rios Itapemirim e Itabapoana, o café foi a cultura pioneira, com exceção da área próxima à foz do Itaperimirim, que foi primeiramente ocupada por fazendas de cana-de- açúcar. Todo o plantio de café dessas regiões iniciou-se com utilização de mão-de-obra escrava. Posteriormente, houve a introdução de imigrantes, principalmente italianos e alemães. Como a introdução do café nessas áreas coincidiu com o final do período escravista e considerando-se, ainda, que o valor do escravo nesse momento era alto e que as fazendas 


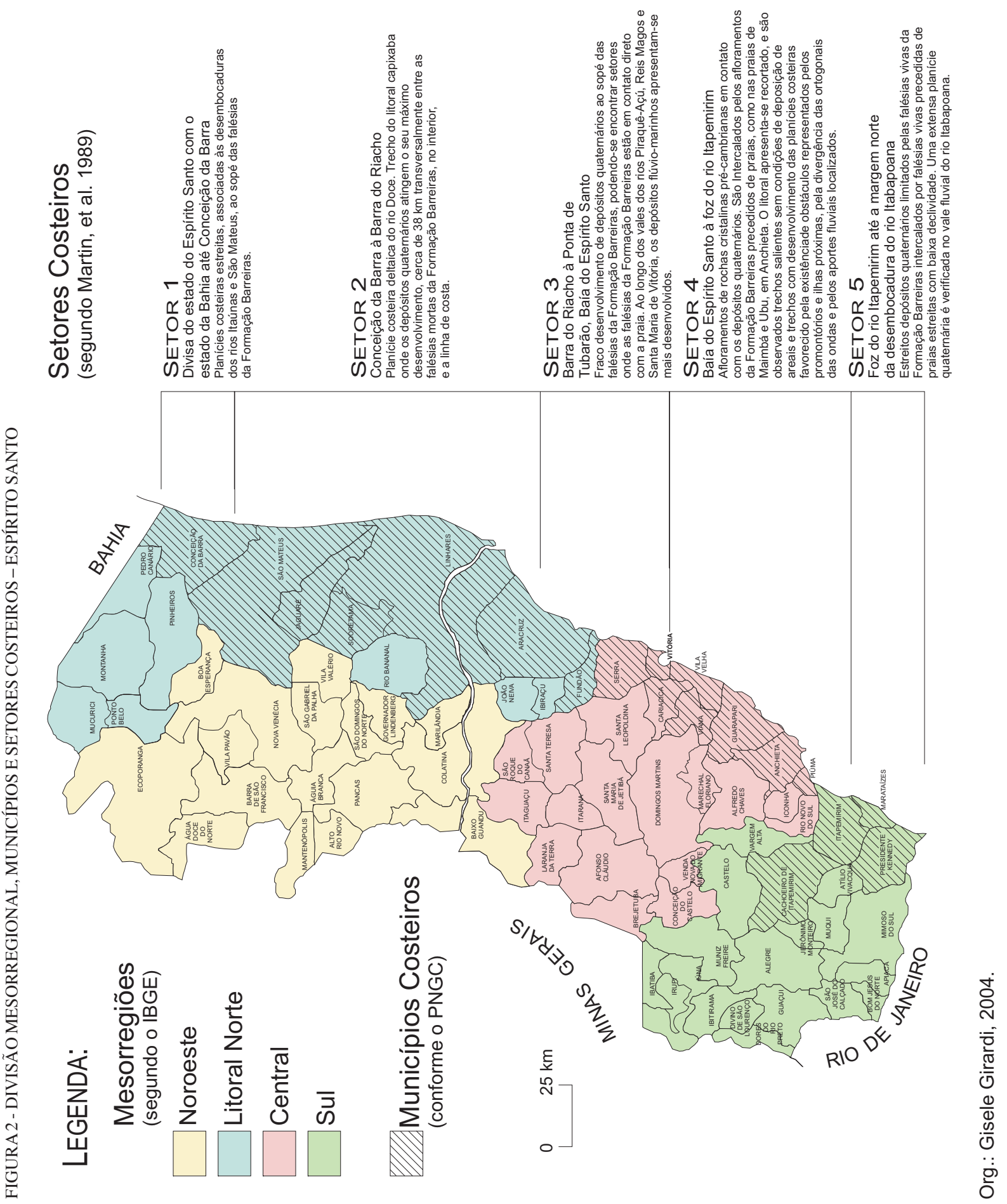


FIGURA 3 - POPULAÇÃO E DESMEMBRAMENTOS MUNICIPAIS NO ESPÍRITO SANTO DE 1950 A 2000
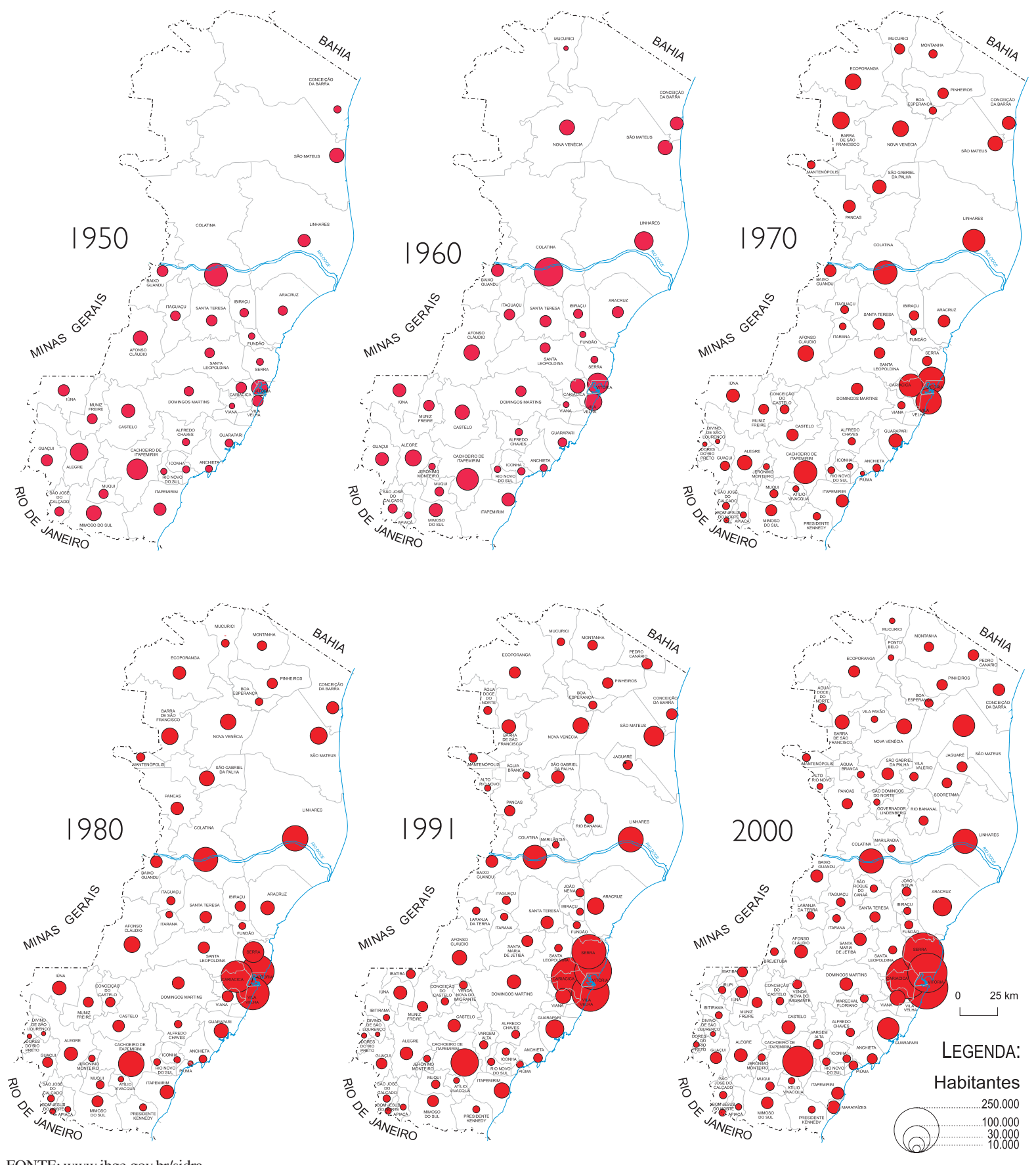

FONTE: www.ibge.gov.br/sidra.

ORG.: Gisele Girardi, 2003. 
eram menos produtivas que as do Vale do Paraíba, não houve condições para a manutenção de grandes fazendas. Na transição para o trabalho livre, conforme Saletto (1996), houve o partilhamento das fazendas, que foram compradas principalmente pelos então colonos. Esse contexto resulta na predominância da pequena propriedade nessas regiões.

Em resumo, a estrutura fundiária do estado é diferencial em função dos processos que engendraram a ocupação do território: ao sul há o predomínio da pequena propriedade familiar, vinculada ao café, e ao norte há a concentração fundiária vinculada a monoculturas.

A Figura 3 mostra a dinâmica populacional do estado entre os anos de 1950 e 2000. Observa-se nos mapas que, a despeito de certa pulverização decorrente de desmembramentos municipais, o estado tem seu crescimento populacional polarizado. Os fatores dessa polarização são também diferenciais.

Em Colatina e em Cachoeiro do Itapemirim, a polarização se deve ao fato de estas localidades terem exercido no passado função de entreposto da expansão do café e terem, posteriormente, abrigado indústrias de beneficiamento de produtos locais, destacando-se, nos dias atuais, com indústrias de bens de consumo, como a têxtil, em Colatina, e a indústria de minerais não metálicos (beneficiamento do mármore e do granito) em Cachoeiro do Itapemirim. Em Linhares, essa polarização é mais recente e articula-se com a construção da BR-101.

Nos municípios conurbados de Vitória, Serra, Cariacica e Vila Velha, a polarização vincula-se com a inserção do estado no quadro econômico e geopolítico nacional, com a instalação dos chamados Grandes Projetos, a partir de 1970, seja como local de instalação física, seja como aglutinador de serviços correlatos aos Grandes Projetos.

Compõem os Grandes Projetos os seguintes empreendimentos: Aracruz Celulose, no município de Aracruz, que produz pasta de celulose a partir de madeira reflorestada nas áreas de monocultura de eucalipto acima mencionadas, bem como as do sul da Bahia, escoadas pela BR-101 ou pelo sistema de barcaças; a Companhia Vale do Rio Doce, em Serra e Vitória, que produz pelotas de ferro a partir de matéria-prima vinda do quadrilátero ferrífero (MG) pela Estrada de Ferro Vitória-Minas; Companhia Siderúrgica de Tubarão, em Vitória, que produz placas de aço, e a Sammarco Mineradora, no município de Anchieta, que produz pelotas de ferro a partir de matéria-prima de Minas Gerais escoada por mineroduto.

Articulada à instalação dos Grandes Projetos, houve a criação ou dinamização dos portos: Portocel, em Barra do
Riacho (Aracruz), especializado em exportação de celulose; Ubu (Anchieta), especializado em exportação de pelotas de ferro; Tubarão, especializado na exportação de minério de ferro e de soja produzida no Centro-Oeste do Brasil e escoada pelo corredor centro-leste; Praia Mole, especializado na exportação de aço. Além desses, há, na baía de Vitória, outros portos de carga geral, destacando-se o Porto de Vitória.

A instalação desse sistema produtivo trouxe consigo uma série de outras indústrias de aporte, tais como as de produtos químicos, construção civil e transportes.

Essa industrialização, temporal e espacialmente concentrada, impulsionou um forte movimento migratório de mão-de-obra, qualificada ou não. Essa, por seu turno, provocou a concentração urbana e criou demandas de serviços variados, o que também funcionou e funciona como motor de outros deslocamentos populacionais para os municípios da Região da Grande Vitória, principalmente.

Esse contingente populacional cria demanda por moradia e serviços nas cidades, mas também promove a ocupação de outras áreas litorâneas para segunda residência ou lazer, o que por sua vez gera processos de valorização da terra, novos fluxos migratórios e demanda de infraestrutura de deslocamento e de serviços.

\section{O Litoral Sul}

A ocupação do Litoral Sul do Espírito Santo, conforme foi apontado, é antiga, porém dispersa, e intensificouse nas últimas décadas, potencializando os impactos sobre o ambiente natural. Na Figura 4 podem ser observados aspectos da ocupação atual.

\section{Aspectos demográficos e urbanização}

Os municípios que compõem o Litoral Sul apresentam dinâmicas de incremento populacional diferenciadas, conforme pode ser observado na Tabela 1.

A tabela dá visibilidade aos processos descritos anteriormente. Os municípios que sediaram ou que se localizavam próximo aos locais de implantação dos Grandes Projetos, nas décadas de 1960/1970, são os que apresentam maior incremento populacional. Cariacica e Vila Velha apresentam crescimento populacional maior que $100 \%$ nesse interstício, o que é explicado pelo fato de se apresentarem como área de expansão de Vitória, posto que este municí- 


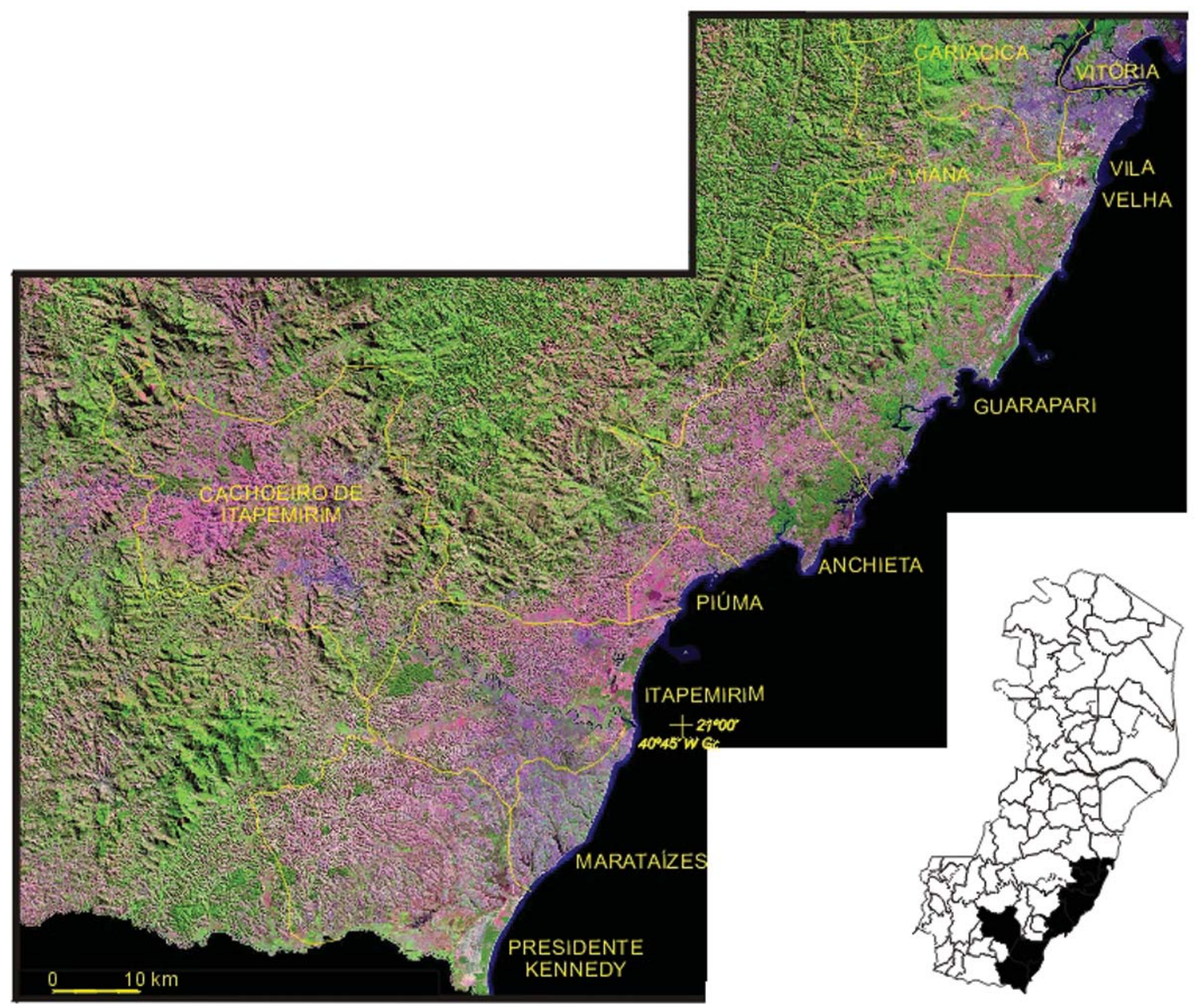

FONTE: Embrapa, 2004.

ORG.: Gisele Girardi, 2003.

pio apresenta limitação de área para expansão. Vitória, Viana e Guarapari apresentam em média $60 \%$ de incremento populacional nessa década, o que tem explicações distintas: em Vitória houve então a ocupação das áreas continentais do município, particularmente com os bairros de Goiabeiras e Jardim da Penha, além do processo de verticalização na ilha. Foi também nesse período que se intensificou a ocupação das encostas dos morros de Vitória. Em Viana, o crescimento é explicado pelo fato de ser cortada e abrigar o entroncamento das duas principais vias de circulação e escoamento de mercadorias do Espírito Santo: a BR-101 e a BR-262. Os eixos destas duas vias são os principais vetores da ocupação urbana de Viana, que também se configura como área de expansão periférica de Vitória. Em Guarapari, o crescimento advém do crescimento da função turística, pois nesse período foi instalada a infraestrutura turística, com urbanização e verticalização situadas na área central do município. Esses processos de adensamento, expansão periférica e de busca de áreas de turismo e veraneio foram responsáveis pelo fato de o Lito- 
GIRARDI, G.; COMETTI, R. de S. Dinâmica do uso e ocupação do solo...

TABELA 1 - POPULAÇÃO DOS MUNICÍPIOS DO LITORAL SUL-ES DE 1960 A 2000

\begin{tabular}{|l|c|c|c|c|c|c|c|c|c|}
\hline \multicolumn{1}{|c|}{ Municípios } & 1960 & 1970 & $\begin{array}{c}\text { TC } \\
(\%) \\
1960 \\
1970\end{array}$ & 1980 & $\begin{array}{c}\text { TC } \\
(\%) \\
1970- \\
1980\end{array}$ & 1991 & $\begin{array}{c}\text { TC (\%) } \\
1980- \\
1991\end{array}$ & 2000 & $\begin{array}{c}\text { TC } \\
(\%) \\
1991- \\
2000\end{array}$ \\
\hline Anchieta & 9.962 & 11.361 & 14,0 & 11.413 & 0,4 & 14.934 & 30,8 & 19.176 & 28,4 \\
\hline $\begin{array}{l}\text { Cachoeiro do } \\
\text { Itapemirim }\end{array}$ & 90.271 & 100.010 & 10,8 & 123.686 & 23,7 & 143.449 & 15,9 & 174.879 & 21,9 \\
\hline Cariacica & 39.608 & 101.422 & 156,0 & 189.099 & 86,4 & 274.532 & 45,2 & 324.285 & 18,1 \\
\hline Guarapari & 14.861 & 24.105 & 62,2 & 38.496 & 59,7 & 61.719 & 60,3 & 88.400 & 43,2 \\
\hline Itapemirim & 31.733 & 28.558 & 24,0 & 35.110 & 22,9 & 44.492 & 26,7 & 28.121 & $32,0^{5}$ \\
\hline Martataízes & - & & - & & - & & - & 30.603 & - \\
\hline Piúma ${ }^{2}$ & - & 3.583 & - & 5.342 & 49,1 & 9.430 & 76,5 & 14.987 & 58,9 \\
\hline Presidente Kennedy & - & 10.789 & - & 9.805 & $-9,1$ & 9.433 & $-3,8$ & 9.555 & 1,3 \\
\hline Viana & 6.571 & 10.529 & 60,2 & 23.440 & 122,6 & 43.866 & 87,1 & 53.452 & 21,8 \\
\hline Vila Velha & 55.589 & 123.742 & 122,6 & 203.406 & 64,4 & 265.586 & 27,8 & 345.965 & 30,3 \\
\hline Vitória & 83.351 & 133.019 & 59,6 & 207.747 & 56,1 & 258.777 & 24,6 & 292.304 & 12,9 \\
\hline Litoral Sul & 292.338 & 547.118 & 87,1 & 847.544 & 54,9 & 1.126 .218 & 28,7 & 1.381 .727 & 22,7 \\
\hline ES & 1.169 .553 & 1.599 .333 & 36,7 & 2.023 .340 & 26,5 & 2.600 .618 & 28,5 & 3.097 .232 & 19,1 \\
\hline
\end{tabular}

NOTAS:

1. Marataízes era distrito de Itapemirim. O desmembramento ocorreu em 1992.

2. Piúma era distrito de Iconha. O desmembramento ocorreu em 1963.

3. Presidente Kennedy era distrito de Itapemirim. O desmembramento ocorreu em 1963.

4. Considerada a população de Presidente Kennedy.

5. Considerada a população de Marataízes.

Fonte: IBGE. Censos Demográficos de 1960, 1970, 1980, 1991 e 2000.

Organização: Renata Cometti, 2003.

ral Sul ter apresentado um crescimento cerca de duas vezes e meia superior ao do Espírito Santo como um todo.

Entre as décadas de 1970 e 1980, houve uma mudança no cenário do crescimento populacional. Os municípios de Viana e Cariacica apresentaram as maiores taxas de crescimento populacional graças ao processo de intensificação da expansão urbana e industrial já mencionado, reforçando o caráter de periferia de Vitória. Guarapari, Vitória e Vila Velha cresceram, em média, $60 \%$ nesse período, mantendo, em termos gerais, as características do processo que ocorreu na década anterior. Começou a se destacar o crescimento populacional de Piúma, em cerca de 50\%, o que coincide com sua valorização como área de veraneio. Nesse período, o Litoral Sul apresentou taxas de crescimento cerca de duas vezes maiores que a do Espírito Santo.
Entre 1980 e 1991 destacaram-se o crescimento de Viana $(87,1 \%)$ e Cariacica $(45,2 \%)$, na lógica da expansão da periferia urbana da capital, e de Piúma (76,5\%) e Guarapari $(60,3 \%)$ por causa do processo de ampliação da atividade de veraneio e turismo. Nesse período, o crescimento populacional do Litoral Sul equilibrou-se com o do Espírito Santo. Já entre 1991 e 2000 houve uma relativa queda ou manutenção das taxas observadas no período anterior. Há que se destacar nesse período o crescimento de Piúma $(58,9 \%)$, cerca de três vezes maior que o do Espírito Santo e duas vezes e meia maior que o do Litoral Sul.

Todo o processo de crescimento até agora abordado refere-se ao crescimento urbano, processo que pode ser mais bem compreendido a partir dos dados apresentados nas Tabelas 2 a 5 . 
TABELA 2 - POPULAÇÃO TOTAL, URBANAE RURAL DOS MUNICÍPIOS DO LITORAL SUL-ES - 1970

\begin{tabular}{|l|c|c|c|c|c|}
\hline Municípios & $\begin{array}{c}\text { População } \\
\text { total }\end{array}$ & $\begin{array}{c}\text { População } \\
\text { rural }\end{array}$ & $\%$ & $\begin{array}{c}\text { População } \\
\text { urbana }\end{array}$ & $\%$ \\
\hline Anchieta & 11.361 & 9.097 & 80,07 & 2.264 & 19,93 \\
\hline Cachoeiro do Itapemirim & 100.010 & 36.940 & 36,94 & 63.070 & 63,06 \\
\hline Cariacica & 101.422 & 32.222 & 31,77 & 69.200 & 68,23 \\
\hline Guarapari & 24.105 & 12.843 & 53,28 & 11.262 & 46,72 \\
\hline Itapemirim & 28.558 & 21.163 & 74,11 & 7.395 & 25,89 \\
\hline Marataízes & - & - & - & - & - \\
\hline Piúma & 3.583 & 1.326 & 37,01 & 2.257 & 62,99 \\
\hline Presidente Kennedy & 10.789 & 10.309 & 95,55 & 480 & 4,45 \\
\hline Viana & 10.529 & 8.909 & 84,61 & 1.620 & 15,39 \\
\hline Vila Velha & 123.742 & 1.892 & 1,53 & 121.850 & 98,47 \\
\hline Vitória & 133.019 & 983 & 0,74 & 132.036 & 99,26 \\
\hline Litoral Sul & 547.118 & 135.684 & 24,80 & 411.434 & 75,20 \\
\hline ES & 1.599 .333 & 877.417 & 54,86 & 721.916 & 45,14 \\
\hline
\end{tabular}

FONTE: IBGE, Censo Demográfico, 1970.

Organização: Renata Cometti, 2003.

TABELA 3 - POPULAÇÃO TOTAL, URBANA E RURAL DOS MUNICÍPIOS DO LITORAL SUL-ES - 1980

\begin{tabular}{|l|c|c|c|c|c|}
\hline Municípios & $\begin{array}{c}\text { População } \\
\text { total }\end{array}$ & $\begin{array}{c}\text { População } \\
\text { rural }\end{array}$ & $\%$ & $\begin{array}{c}\text { População } \\
\text { urbana }\end{array}$ & $\%$ \\
\hline Anchieta & 11.413 & 5.282 & 46,28 & 6.131 & 53,72 \\
\hline Cachoeiro do Itapemirim & 123.686 & 33.219 & 26,86 & 90.467 & 73,14 \\
\hline Cariacica & 189.099 & 3.801 & 2,01 & 185.298 & 97,99 \\
\hline Guarapari & 38.500 & 6.365 & 16,53 & 32.135 & 83,47 \\
\hline Itapemirim & 35.113 & 17.753 & 50,56 & 17.360 & 49,44 \\
\hline Marataízes & - & - & - & - & - \\
\hline Piúma & 5.345 & 1.416 & 26,49 & 3.929 & 73,51 \\
\hline Presidente Kennedy & 9.801 & 8.778 & 89,56 & 1.023 & 10,44 \\
\hline Viana & 23.440 & 4.809 & 20,52 & 18.631 & 79,48 \\
\hline Vila Velha & 203.401 & 1.026 & 0,50 & 202.375 & 99,50 \\
\hline Vitória & 207.736 & 0 & 0 & 207.736 & 100,00 \\
\hline Litoral Sul & 847.534 & 82.449 & 9,73 & 765.085 & 90,27 \\
\hline ES & 2.023 .340 & 729.962 & 36,08 & 1.293 .378 & 63,92 \\
\hline
\end{tabular}

FONTE: IBGE. Censo Demográfico, 1980.

Organização: Renata Cometti, 2003. 
TABELA 4 - POPULAÇÃO TOTAL, URBANAE RURAL DOS MUNICÍPIOS DO LITORAL SUL- ES - 1991

\begin{tabular}{|l|c|c|c|c|c|}
\hline Municípios & $\begin{array}{c}\text { População } \\
\text { total }\end{array}$ & $\begin{array}{c}\text { População } \\
\text { rural }\end{array}$ & $\%$ & $\begin{array}{c}\text { População } \\
\text { urbana }\end{array}$ & $\%$ \\
\hline Anchieta & 14.934 & 6.141 & 46,28 & 8.793 & 53,72 \\
\hline Cachoeiro do Itapemirim & 143.449 & 26.330 & 26,86 & 117.119 & 73,14 \\
\hline Cariacica & 274.532 & 13.448 & 2,01 & 261.084 & 97,99 \\
\hline Guarapari & 61.719 & 6.523 & 16,53 & 55.196 & 83,47 \\
\hline Itapemirim & 44.492 & 17.429 & 50,56 & 27.063 & 49,44 \\
\hline Marataízes & - & - & - & - & - \\
\hline Piúma & 9.430 & 868 & 26,49 & 8.562 & 73,51 \\
\hline Presidente Kennedy & 9.433 & 7.519 & 89,56 & 1.914 & 10,44 \\
\hline Viana & 43.866 & 3.978 & 20,52 & 39.888 & 79,48 \\
\hline Vila Velha & 265.586 & 1.350 & 0,50 & 264.236 & 99,50 \\
\hline Vitória & 258.777 & 0 & 0 & 258.777 & 100,00 \\
\hline Litoral Sul & 1.126 .218 & 83.586 & 7,42 & 1.042 .632 & 92,58 \\
\hline ES & 2.600 .618 & 676.030 & 25,99 & 1.924 .588 & 74,01 \\
\hline
\end{tabular}

FONTE: IBGE. Censo Demográfico, 1991.

Organização: Renata Cometti, 2003.

TABELA 5 - POPULAÇÃO TOTAL, URBANAE RURAL DOS MUNICÍPIOS DO LITORAL SUL-ES - 2000

\begin{tabular}{|l|c|c|c|c|c|}
\hline Municípios & $\begin{array}{c}\text { População } \\
\text { total }\end{array}$ & $\begin{array}{c}\text { População } \\
\text { rural }\end{array}$ & $\%$ & $\begin{array}{c}\text { População } \\
\text { urbana }\end{array}$ & $\%$ \\
\hline Anchieta & 19.176 & 5.965 & 31,11 & 13.211 & 68,89 \\
\hline Cachoeiro do Itapemirim & 174.879 & 19.478 & 11,14 & 155.401 & 88,86 \\
\hline Cariacica & 324.285 & 11.305 & 3,49 & 312.980 & 96,51 \\
\hline Guarapari & 88.400 & 5.811 & 6,57 & 82.589 & 93,43 \\
\hline Itapemirim & 28.121 & 11.988 & 42,63 & 16.133 & 57,37 \\
\hline Marataízes & 30.603 & 6.846 & 22,37 & 23.757 & 77,63 \\
\hline Piúma & 14.987 & 886 & 5,91 & 14.101 & 94,09 \\
\hline Presidente Kennedy & 9.555 & 7.025 & 73,52 & 2.530 & 26,48 \\
\hline Viana & 53.452 & 3.855 & 7,21 & 49.597 & 92,79 \\
\hline Vila Velha & 345.965 & 1.340 & 0,39 & 344.625 & 99,61 \\
\hline Vitória & 292.304 & 0 & 0 & 292.304 & 100,00 \\
\hline Litoral Sul & 1.381 .727 & 74.499 & 5,39 & 1.307 .228 & 94,61 \\
\hline ES & 3.097 .232 & 634.183 & 20,48 & 2.463 .049 & 79,52 \\
\hline
\end{tabular}

FONTE: IBGE. Censo Demográfico, 2000.

Organização: Renata Cometti, 2003. 
Pode-se observar que todos os municípios mencionados anteriormente, por apresentarem crescimento populacional mais significativo, correspondem aos municípios que hoje apresentam taxa de urbanização maior que 92\%, como pode ser observado na Tabela 6. Anchieta, Itapemirim e Marataízes, apesar de apresentarem elevado grau de urbanização próximo à orla marítima, apresentam significativas áreas de uso agropecuário. Presidente Kennedy, por seu turno, é ainda área predominantemente rural e é o único município praiano do Litoral Sul cuja sede não se localiza na orla marítima.

É também relevante observar a alta densidade demográfica dos municípios francamente urbano-industriais, como Vitória, Vila Velha e Cariacica, indicador de ocupação adensada, seja por habitações irregulares ou pelo processo de verticalização.

Corroboram a análise os dados sobre a ocupação dos domicílios apresentados na Tabela 7.
Cachoeiro do Itapemirim, Cariacica, Viana, Vila Velha e Vitória apresentam mais de $84 \%$ dos domicílios ocupados, indicando a predominância de população fixa, o que se relaciona aos aspectos econômicos locais. Tais municípios sediam 107 das 150 maiores empresas (em receita operacional bruta) do Espírito Santo (FINDES, 1999), o que fixa população graças a empregos diretos e indiretos e a serviços correlatos, formais ou não.

Por outro lado, os municípios de Anchieta, Guarapari, Itapemirim, Marataízes e Piúma apresentam mais de 35\% dos domicílios vagos ou de uso ocasional, o que indicia a atividade de veraneio. Desse conjunto, Piúma se destaca por apresentar 57,19\% dos domicílios na situação mencionada.

A estrutura do emprego apresenta correlações claras com o grau de ocupação dos domicílios e permite avançar na análise da própria estrutura social do lugar. Vitória apresenta característica de centralidade, pois tem 47,5\% dos

TABELA 6 - POPULAÇÃO, DENSIDADE DEMOGRÁFICAE URBANIZAÇÃO DOS MUNICÍPIOS DO LITORAL SUL- ES 2000

\begin{tabular}{|l|c|c|c|c|c|c|c|}
\hline Municípios & $\begin{array}{c}\text { População } \\
\text { total }\end{array}$ & $\begin{array}{c}\text { População } \\
\text { rural }\end{array}$ & $\%$ & $\begin{array}{c}\text { População } \\
\text { urbana }\end{array}$ & Área $\left(\mathrm{Km}^{2}\right)$ & $\begin{array}{c}\text { Densidade } \\
\text { demográfica } \\
(\text { hab/km²) }\end{array}$ & $\begin{array}{c}\text { Taxa de } \\
\text { urbanização } \\
(\%)\end{array}$ \\
\hline Anchieta & 19.176 & 5.965 & 31,0 & 13.211 & 416,91 & 45,97 & 69,0 \\
\hline $\begin{array}{l}\text { Cachoeiro do } \\
\text { Itapemirim }\end{array}$ & 174.879 & 19.478 & 11,1 & 155.401 & 880,00 & 198,73 & 88,9 \\
\hline Cariacica & 324.285 & 11.305 & 3,5 & 312.980 & 273,00 & $1.187,86$ & 96,5 \\
\hline Guarapari & 88.400 & 5.811 & 6,6 & 82.589 & 580,27 & 152,34 & 93,4 \\
\hline Itapemirim & 28.121 & 11.988 & 42,6 & 16.133 & 553,98 & 50,76 & 57,4 \\
\hline Marataízes & 30.603 & 6.846 & 22,4 & 23.757 & 134,96 & 226,76 & 77,6 \\
\hline Piúma & 14.987 & 886 & 5,9 & 14.101 & 72,94 & 205,47 & 94,1 \\
\hline Presidente Kennedy & 9.555 & 7.025 & 73,5 & 2.530 & 586,72 & 16,28 & 26,5 \\
\hline Viana & 53.452 & 3.855 & 7,2 & 49.597 & 294,00 & 181,81 & 92,8 \\
\hline Vila Velha & 345.965 & 1.340 & 0,4 & 344.625 & 218,22 & $1.585,39$ & 99,6 \\
\hline Vitória & 292.304 & - & - & 292.304 & 88,76 & $3.293,19$ & 100,0 \\
\hline Litoral Sul & 1.381 .727 & 74.499 & 5,4 & 1.307 .228 & $4.099,76$ & 337,03 & 94,5 \\
\hline ES & 3.097 .232 & 634.183 & 20,5 & 2.463 .049 & $46.184,10$ & 67,06 & 79,5 \\
\hline
\end{tabular}

FONTE: IBGE. Censo Demográfico, 2000.

Organização: Renata Cometti, 2003. 
TABELA 7 - CONDIÇÃO DE OCUPAÇÃO DOS DOMICÍLIOS DO LITORAL SUL-ES

\begin{tabular}{|c|c|c|c|c|c|c|c|c|c|c|}
\hline \multirow{3}{*}{ Municípios } & \multicolumn{9}{|c|}{ Domicílios } & \multirow{3}{*}{$\begin{array}{l}\text { Média de } \\
\text { morado- } \\
\text { res por } \\
\text { domicílio } \\
\text { ocupado }\end{array}$} \\
\hline & \multirow[b]{2}{*}{ Total } & \multirow[b]{2}{*}{$\begin{array}{c}\text { Ocupa- } \\
\text { dos }\end{array}$} & \multirow[b]{2}{*}{$\%$} & \multicolumn{6}{|c|}{ Não ocupados } & \\
\hline & & & & $\begin{array}{c}\text { Fecha- } \\
\text { dos }\end{array}$ & $\%$ & $\begin{array}{c}\text { Uso } \\
\text { ocasio- } \\
\text { nal }\end{array}$ & $\%$ & Vagos & $\%$ & \\
\hline Anchieta & 8.025 & 4.983 & 62,09 & 55 & 0,69 & 1.984 & 24,72 & 947 & 11,80 & 3,85 \\
\hline Cachoeiro do Itapemirim & 55.989 & 48.598 & 86,80 & 390 & 0,70 & 878 & 1,57 & 6.077 & 10,85 & 3,60 \\
\hline Cariacica & 102.368 & 88.315 & 86,27 & 869 & 0,85 & 987 & 0,96 & 12.161 & 11,88 & 3,67 \\
\hline Guarapari & 49.460 & 24.604 & 49,75 & 606 & 1,23 & 18.439 & 37,28 & 5.698 & 11,52 & 3,59 \\
\hline Itapemirim & 11.841 & 7.460 & 63,00 & 117 & 0,99 & 2.434 & 20,56 & 1.807 & 15,26 & 3,77 \\
\hline Marataízes & 15.524 & 8.396 & 54,08 & 33 & 0,21 & 5.482 & 35,31 & 1.576 & 10,15 & 3,64 \\
\hline Piúma & 9.914 & 4.165 & 42,01 & 28 & 0,28 & 4.368 & 44,06 & 1.302 & 13,13 & 3,60 \\
\hline Presidente Kennedy & 3.642 & 2.638 & 72,43 & - & - & 340 & 9,34 & 653 & 17,93 & 3,62 \\
\hline Viana & 16.396 & 14.239 & 86,84 & 98 & 0,60 & 361 & 2,20 & 1.690 & 10,31 & 3,75 \\
\hline Vila Velha & 117.863 & 99.280 & 84,23 & 1.549 & 1,31 & 3.472 & 2,95 & 13.460 & 11,42 & 3,48 \\
\hline Vitória & 100.961 & 85.810 & 84,99 & 1.233 & 1,22 & 2.694 & 2,67 & 11.139 & 11,03 & 3,41 \\
\hline Litoral Sul & 491.983 & 388.488 & 78,96 & 4.978 & 1,01 & 41.439 & 8,42 & 56.510 & 11,48 & 3,56 \\
\hline
\end{tabular}

FONTE: IBGE

Organização: Renata Cometti, 2003.

empregos nas atividades de comércio, serviços ligados ao setor imobiliário, administração pública e educação. Vila Velha, Viana, Cariacica e Cachoeiro do Itapemirim apresentam mais de $50 \%$ dos empregos nas atividades de comércio, indústria da transformação, construção e serviços domésticos, o que aponta características de áreas urbanoindustriais periféricas em expansão.

Anchieta, Itapemirim e Marataízes apresentam cerca de $50 \%$ dos empregos nas atividades de agricultura, comércio, construção e pesca, o que contribui para analisálos como municípios nos quais atividades tradicionais coexistem com atividades voltadas ao turismo e ao veraneio.

Guarapari e Piúma apresentam mais de 50\% dos empregos em atividades francamente voltadas ao turismo e ao veraneio: comércio, construção, serviços domésticos, alojamento e alimentação e, no caso de Piúma, destaca-se ainda a atividade de produção de artesanato de conchas. Já Presidente Kennedy destaca-se de todos os outros municípios por apresentar mais de $50 \%$ dos empregos na agropecuária.

\section{Aspectos econômicos e infra-estruturais}

A composição do PIB municipal, expressa na Tabela 8 , contribui para a reflexão sobre os agrupamentos de municípios que vêm sendo construídos na presente análise.

Os municípios que têm seu PIB fortemente concentrado no setor terciário (mais de 95\%) são os de Guarapari e Piúma, o que nos fornece um elemento adicional para compreender seus vínculos com a atividade turística e de veraneio. Os municípios de Cachoeiro do Itapemirim, Cariacica, Viana, Vila Velha e Vitória apresentam a maior parte de seus PIBs no setor terciário, seguido do secundário. Considerando a demanda por serviços das áreas urbano-industriais, a porcentagem do PIB no terciário, ainda que não seja a predominante nesses municípios, indica a importância da indústria em sua economia. Além da informação anteriormente apontada, da presença de mais de $70 \%$ das maiores empresas do estado nesses municípios, é importante destacar sua diversificação. Itapemirim e Anchieta, ao contrário, ainda que apresentem porcentagens significa- 
TABELA 8 - COMPOSIÇÃO SETORIAL DO PIB NOS MUNICÍPIOS DO LITORAL SUL DO ES - 1998

\begin{tabular}{|c|c|c|c|c|c|c|c|c|c|}
\hline \multirow[b]{2}{*}{ Município } & \multicolumn{2}{|c|}{ Setor primário } & \multicolumn{2}{|c|}{ Setor secundário } & \multicolumn{2}{|c|}{ Setor terciário } & \multicolumn{3}{|c|}{ PIB municipal total } \\
\hline & $\%$ & $\mathrm{R} \$ 1.000$ & $\%$ & $\mathrm{R} \$ 1.000$ & $\%$ & $\mathrm{R} \$ 1.000$ & $\begin{array}{c}\text { Preços } \\
\text { básicos } \\
\text { em R\$ } \\
1.000\end{array}$ & \begin{tabular}{|c|}
$\%$ do \\
PIB \\
do ES
\end{tabular} & $\begin{array}{c}\text { Preços de } \\
\text { mercado } \\
\text { em R } \$ \\
1.000\end{array}$ \\
\hline Anchieta & 2,85 & 9.997 & 78,96 & 276.182 & 18,19 & 63.596 & 349.775 & 2,36 & 410.407 \\
\hline Cachoeiro de Itapemirim & 2,48 & 20.890 & 45,30 & 382.128 & 47,78 & 440.585 & 843.603 & 5,70 & 989.839 \\
\hline Cariacica & 0,26 & 2.225 & 28,30 & 239.630 & 71,44 & 604.824 & 846.680 & 5,72 & 993.448 \\
\hline Guarapari & 3,33 & 9.018 & 3,13 & 8.477 & 95,54 & 253.173 & 270.668 & 1,83 & 317.587 \\
\hline Itapemirim & 12,44 & 12.126 & 36,29 & 35.363 & 51,27 & 49.952 & 97.441 & 0,66 & 114.332 \\
\hline Marataízes & 10,88 & 7.184 & 0,69 & 460 & 88,43 & 58.375 & 66.018 & 0,45 & 77.462 \\
\hline Piúma & 2,17 & 861 & 0,92 & 366 & 96,91 & 38.482 & 39.709 & 0,27 & 46.592 \\
\hline Presidente Kennedy & 36,88 & 10.617 & 0,37 & 106 & 62,75 & 18.059 & 28.782 & 0,19 & 33.772 \\
\hline Viana & 2,43 & 5.674 & 45,28 & 105.440 & 52,29 & 121.748 & 232.862 & 1,57 & 273.228 \\
\hline Vila Velha & 0,07 & 901 & 36,43 & 452.084 & 63,50 & 788.146 & 1.241 .131 & 8,39 & 1.456 .276 \\
\hline Vitória & 0,00 & 0,00 & 29,52 & 931.422 & 70,48 & 2.223 .343 & 3.154 .765 & 21,32 & 3.701 .632 \\
\hline
\end{tabular}

FONTE: Ipes (disponível em www.ipes.es.gov.br, acesso em setembro de 2004)

Organização: Gisele Girardi, 2004.

tivas do PIB no setor secundário, não apresentam diversificação industrial. No caso do município de Anchieta, o PIB gerado no secundário vincula-se à presença da Sammarco Mineradora S/A, indústria de pelotização de minério de ferro e, no caso de Itapemirim, vincula-se à indústria Paineiras, do setor químico, voltada à produção de açúcar e álcool.

Marataízes e Presidente Kennedy têm como característica comum o setor terciário com a maior porcentagem, seguido do setor primário. Esse fator é particularmente importante em Presidente Kennedy, que tem sua economia voltada para a agropecuária e o setor terciário é para ela direcionada, diferentemente de Marataízes, que divide o setor terciário entre atividades voltadas ao setor agropecuário e atividades relacionadas ao veraneio e turismo.

Na Tabela 9 podemos observar a distribuição per capita do PIB, que reproduz algumas das distorções acima apontadas.

A variável renda per capita é um indicador da possibilidade de acesso a serviços. É importante, portanto, analisá-la conjuntamente com variáveis que indicam nível de saúde da população. Uma dessas variáveis é a de abastecimento de água, apresentada na Tabela 10.

Sobre o abastecimento de água pela rede geral, podemos observar que a maioria dos municípios do Litoral Sul tem mais de $80 \%$ dos domicílios abastecidos por rede ge- ral. A porcentagem de atendimento dos domicílios do Litoral Sul pela rede geral supera, em muito, a média do estado. Exceções são observadas em Anchieta (71,93\%), Itapemirim $(64,34 \%)$ e Presidente Kennedy $(38,45 \%)$. Ainda que haja coincidência entre as menores porcentagens de abastecimento por rede geral e menores taxas de urbanização, é importante apontar que, no que se refere à comparação com a renda per capita, as distorções geradas pela existência de grandes empresas em Anchieta e Itapemirim se evidenciam.

$\mathrm{O}$ atendimento de água pela rede geral dos domicílios ocupados urbanos e sua comparação com o significado deste serviço em relação à porcentagem de domicílios ocupados podem fornecer um indicador de possíveis colapsos no abastecimento de água em períodos de temporada, como pode ser observado na Tabela 11.

Observa-se que Presidente Kennedy apresenta o menor índice de domicílios urbanos com abastecimento de água pela rede geral, o que é um indicador da precariedade do saneamento. No entanto, a taxa de ocupação dos domicílios neste município revela pouca variação sazonal de contingente populacional. Situação diferenciada pode ser observada para os municípios de Anchieta, Guarapari, Itapemirim, Marataízes e Piúma, pois tais municípios têm taxas de abastecimento de domicílios urbanos pela rede 
TABELA 9 - RENDA PER CAPITA DOS MUNICÍPIOS DO LITORAL SUL-ES - 1998

\begin{tabular}{|l|c|c|c|}
\hline Município & $\begin{array}{c}\text { PIB } \\
\text { (Preços de mercado) }\end{array}$ & $\begin{array}{c}\text { População } \\
\text { (estimativa para 1998) }\end{array}$ & $\begin{array}{c}\text { Renda per capita } \\
\text { (em R\$ ) }\end{array}$ \\
\hline Anchieta & 410.407 & 18.240 & 22.500 \\
\hline Cachoeiro de Itapemirim & 989.839 & 153.559 & 6.450 \\
\hline Cariacica & 993.448 & 313.427 & 3.170 \\
\hline Guarapari & 317.587 & 77.776 & 4.080 \\
\hline Itapemirim & 114.332 & 26.560 & 4.300 \\
\hline Marataízes & 77.462 & 27.499 & 2.820 \\
\hline Piúma & 46.592 & 12.960 & 3.600 \\
\hline Presidente Kennedy & 33.772 & 9.699 & 3.480 \\
\hline Viana & 273.228 & 50.100 & 5.450 \\
\hline Vila Velha & 1.456 .276 & 312.059 & 4.670 \\
\hline Vitória & 3.701 .632 & 269.135 & 13.750 \\
\hline
\end{tabular}

FONTE: Ipes (disponível em www.ipes.es.gov.br, acesso em setembro de 2004)

Organização: Gisele Girardi, 2004.

TABELA 10 - ABASTECIMENTO DE ÁGUA POR DOMICÍLIO PARTICULAR PERMANENTE DO LITORAL SUL-ES - 2002

\begin{tabular}{|c|c|c|c|c|c|c|c|}
\hline \multirow[b]{2}{*}{ Municípios } & \multirow{2}{*}{\begin{tabular}{|c|} 
Total de \\
domicí- \\
lios \\
ocupado \\
s \\
\end{tabular}} & \multicolumn{6}{|c|}{ Forma de abastecimento de água } \\
\hline & & $\begin{array}{l}\text { Rede } \\
\text { geral }\end{array}$ & $\%$ & $\begin{array}{l}\text { Poço ou } \\
\text { nascente }\end{array}$ & $\%$ & Outros & $\%$ \\
\hline Anchieta & 4.983 & 3.577 & 71,93 & 1.372 & 27,59 & 24 & 0,48 \\
\hline Cachoeiro do Itapemirim & 48.598 & 44.245 & 91,22 & 3.936 & 8,11 & 324 & 0,67 \\
\hline Cariacica & 88.315 & 84.233 & 95,62 & 3.546 & 4,03 & 313 & 0,36 \\
\hline Guarapari & 24.604 & 20.738 & 84,52 & 3.464 & 14,12 & 333 & 1,36 \\
\hline Itapemirim & 7.460 & 4.738 & 64,34 & 2.528 & 34,33 & 98 & 1,33 \\
\hline Marataízes & 8.396 & 6.735 & 80,31 & 1.608 & 19,17 & 43 & 0,51 \\
\hline Piúma & 4.165 & 3.804 & 92,46 & 290 & 7,05 & 20 & 0,49 \\
\hline Presidente Kennedy & 2.638 & 1.007 & 38,45 & 1.567 & 59,83 & 45 & 1,72 \\
\hline Viana & 14.239 & 12.129 & 85,48 & 1.988 & 14,01 & 73 & 0,51 \\
\hline Vila Velha & 99.280 & 97.024 & 98,06 & 1.280 & 1,29 & 635 & 0,64 \\
\hline Vitória & 85.810 & 84.986 & 99,33 & 391 & 0,46 & 181 & 0,21 \\
\hline Litoral Sul & 388.488 & 363.216 & 93,49 & 21.970 & 5,65 & 2.089 & 0,54 \\
\hline ES & 841.096 & 679.279 & 80,76 & 152.019 & 18,07 & 9.798 & 1,16 \\
\hline
\end{tabular}

FONTE: IBGE. Censo Demográfico, 2000.

Organização: Renata Cometti, 2003. 
TABELA 11 - ABASTECIMENTO DE ÁGUA NOS DOMICÍLIOS OCUPADOS URBANOS DO LITORAL SUL-ES - 2002

\begin{tabular}{|l|c|c|c|c|c|c|c|}
\hline Municípios & $\begin{array}{c}N^{\circ} \text { total de } \\
\text { domicílios }\end{array}$ & $\begin{array}{c}N^{\circ} \text { de } \\
\text { domicílios } \\
\text { ocupados }\end{array}$ & $\begin{array}{c}\text { \% de } \\
\text { domicílios } \\
\text { ocupados }\end{array}$ & $\begin{array}{c}\mathrm{N}^{\circ} \text { de } \\
\text { domicílios } \\
\text { ocupados } \\
\text { urbanos }\end{array}$ & $\begin{array}{c}\mathrm{N}^{\circ} \text { de de } \\
\text { domicílios } \\
\text { ocupados } \\
\text { urbanos }\end{array}$ & $\begin{array}{c}\text { domicílios de domicílios } \\
\text { ocupados } \\
\text { urbanos com } \\
\text { abastecimento } \\
\text { de água pela } \\
\text { rede geral }\end{array}$ & $\begin{array}{c}\text { ocupados } \\
\text { urbanos com } \\
\text { abastecimento } \\
\text { de água pela } \\
\text { rede geral }\end{array}$ \\
\hline Anchieta & 8.025 & 4.983 & 62,09 & 3.693 & 74,11 & 3.477 & 94,15 \\
\hline $\begin{array}{l}\text { Cachoeiro do } \\
\text { Itapemirim }\end{array}$ & 55.989 & 48.598 & 86,80 & 43.702 & 89,92 & 42.595 & 97,46 \\
\hline Cariacica & 102.368 & 88.315 & 86,27 & 85.134 & 96,40 & 81.914 & 96,22 \\
\hline Guarapari & 49.460 & 24.604 & 49,75 & 22.975 & 93,38 & 20.786 & 90,47 \\
\hline Itapemirim & 11.841 & 7.460 & 63,00 & 4.278 & 57,35 & 4.080 & 95,37 \\
\hline Marataízes & 15.524 & 8.396 & 54,08 & 6.645 & 79,14 & 6.453 & 97,11 \\
\hline Piúma & 9.914 & 4.165 & 42,01 & 3.882 & 93,21 & 3.736 & 96,24 \\
\hline $\begin{array}{l}\text { Presidente } \\
\text { Kennedy }\end{array}$ & 3.642 & 2.638 & 72,43 & 730 & 27,67 & 612 & 83,83 \\
\hline Viana & 16.396 & 14.239 & 86,84 & 13.170 & 92,49 & 12.075 & 91,68 \\
\hline Vila Velha & 117.863 & 99.280 & 84,23 & 98.574 & 99,29 & 96.970 & 98,37 \\
\hline Vitória & 100.961 & 85.810 & 84,99 & 85.514 & 99,65 & 85.054 & 99,46 \\
\hline Litoral Sul & 491.983 & 388.488 & 78,96 & 368.297 & 94,80 & 357.752 & 97,14 \\
\hline
\end{tabular}

FONTE: IBGE. Censo Demográfico, 2000.

Organização: Renata Cometti, 2003.

geral entre $90 \%$ e $97 \%$, o que pode indicar atendimento razoável à população moradora. Contudo, as taxas de ocupação dos domicílios variam de 42,01\% (em Piúma) a 63,00\% (em Itapemirim), indicando significativa variação sazonal da população para turismo e veraneio, e possíveis déficits no abastecimento de água.

Nos municípios de Vitória, Vila Velha, Viana, Cariacica e Cachoeiro do Itapemirim, esta situação não se apresenta, pois as taxas de ocupação dos domicílios são relativamente altas, indicando pouca variação sazonal da população.

A coleta do lixo é outro importante indicador do nível de infra-estrutura dos municípios, conforme pode ser observado na Tabela 12.

A situação em relação à coleta de lixo assemelha-se muito com a já descrita sobre o abastecimento de água. Há que se destacar dois conjuntos de municípios pelas suas características e possível sazonalidade do problema do lixo. Anchieta, Guarapari e Marataízes apresentam a porcentagem de domicílios com coleta de lixo flutuante, ou seja, ao se considerar apenas a informação sobre os domicílios ocupados, a porcentagem de domicílios com coleta de lixo é maior; se se considera a somatória dos domicílios ocupados com os de uso ocasional, a relação se inverte, o que indicia o agravamento do problema do destino do lixo em períodos de ocupação intensa, nas temporadas.

Em Viana e Cariacica, a porcentagem de domicílios com coleta de lixo é sempre menor, tanto se se consideram somente os domicílios ocupados quanto a somatória dos ocupados com os de uso ocasional, o que revela um problema crônico e recorrente da condição de expansão periférica desses dois municípios.

Presidente Kennedy e Itapemirim apresentam situação semelhante à dos municípios ultimamente citados, mas apresentam os maiores valores porcentuais de lixo queimado na propriedade, prática comum em áreas rurais. Contudo, assim como Cariacica e Viana, Presidente Kennedy apresenta porcentagem significativa de lixo jogado em terreno baldio ou logradouro, o que indica claramente deficiência na infra-estrutura urbana. 
TABELA 12 - DESTINO DO LIXO POR DOMICÍLIO PARTICULAR PERMANENTE NOS MUNICÍPIOS DO LITORAL SUL-ES 2000

\begin{tabular}{|c|c|c|c|c|c|c|c|c|c|}
\hline \multirow[b]{2}{*}{ Municípios } & \multirow[b]{2}{*}{$\begin{array}{c}\text { Total de } \\
\text { domicílios } \\
\text { ocupados }\end{array}$} & \multicolumn{8}{|c|}{ Destino do lixo } \\
\hline & & Coletado & $\%$ & $\begin{array}{c}\text { Queima- } \\
\text { do na } \\
\text { proprie- } \\
\text { dade }\end{array}$ & $\%$ & \begin{tabular}{|c|} 
Jogado \\
em \\
terreno \\
baldio ou \\
logra- \\
douro \\
\end{tabular} & $\%$ & $\begin{array}{l}\text { Outro } \\
\text { destino }\end{array}$ & $\%$ \\
\hline Anchieta & 4.973 & 3.695 & 74,30 & 1.081 & 21,74 & 132 & 2,65 & 65 & 1,31 \\
\hline Cachoeiro do Itapemirim & 48.505 & 44.238 & 91,20 & 3.689 & 7,61 & 390 & 0,80 & 188 & 0,39 \\
\hline Cariacica & 88.092 & 68.137 & 77,35 & 12.097 & 13,73 & 6.494 & 7,37 & 1364 & 1,55 \\
\hline Guarapari & 24.535 & 20.950 & 85,39 & 2.511 & 10,23 & 766 & 3,12 & 308 & 1,26 \\
\hline Itapemirim & 7.364 & 4.237 & 57,54 & 2.649 & 35,97 & 372 & 5,05 & 106 & 1,44 \\
\hline Marataízes & 8.386 & 6.271 & 74,78 & 1.749 & 20,86 & 316 & 3,77 & 50 & 0,59 \\
\hline Piúma & 4.114 & 3.768 & 91,59 & 306 & 7,44 & 28 & 0,68 & 12 & 0,29 \\
\hline Presidente Kennedy & 2.619 & 584 & 22,30 & 1.749 & 66,78 & 228 & 8,71 & 58 & 2,22 \\
\hline Viana & 14.190 & 10.297 & 72,57 & 2.848 & 20,07 & 851 & 6,00 & 194 & 1,36 \\
\hline Vila Velha & 98.939 & 95.158 & 96,18 & 1.781 & 1,80 & 1.423 & 1,44 & 577 & 0,58 \\
\hline Vitória & 85.558 & 85.180 & 99,56 & 181 & 0,21 & 143 & 0,17 & 54 & 0,06 \\
\hline \multicolumn{10}{|l|}{ Litoral Sul } \\
\hline ES & & & & & & & & & \\
\hline
\end{tabular}

FONTE: IBGE. Censo Demográfico, 2000.

Organização: Renata Cometti, 2003.

Outro importante indicador de saúde é a existência de banheiros e o destino do esgoto, conforme pode ser observado na Tabela 13.

Somente Vitória apresenta déficit de infra-estrutura de esgoto de menos de 2\%. Em Anchieta e Vila Velha, esse déficit é de aproximadamente 6\%, e em Cachoeiro do Itapemirim e Marataízes é de aproximadamente 12\%. Todos os outros municípios do Litoral Sul apresentam taxas preocupantes de esgoto a céu aberto, variando de $11 \%$ a $22 \%$. As porcentagens significativas de domicílios sem banheiro ou sanitário em Presidente Kennedy $(13,13 \%)$, Itapemirim (6,31\%) e Marataízes (5,22\%) relacionam-se à relevância do setor primário nesses municípios.

\section{Aspectos do desenvolvimento humano e municipal}

Os dados anteriormente analisados contribuem para a explicação do quadro do IDH apresentado na Tabela 14.

A partir desse indicador, é possível afirmar que o Litoral Sul é uma região de muitos contrastes. Abarca os dois mais altos IDHs do Espírito Santo (Vila Velha - 0,817 e Vitória - 0,856) e também o quarto menor IDH do estado (Presidente Kennedy - 0,674). Todos os sub-índices do IDH-M apresentam comportamento semelhante, exceto o de longevidade, no qual Anchieta, Guarapari e Piúma apresentam os quartos maiores índices do estado, e Itapemirim, 
TABELA 13 - DOMICÍLIO PARTICULAR PERMANENTE, COM EXISTÊNCIA DE BANHEIRO OU SANITÁRIO E DESTINO DO ESGOTO NOS MUNICÍPIOS DO LITORAL SUL DO ES - 2000

\begin{tabular}{|c|c|c|c|c|c|c|c|}
\hline \multirow[b]{3}{*}{ Municípios } & \multirow{3}{*}{$\begin{array}{c}\text { Total de } \\
\text { domicílios } \\
\text { ocupados }\end{array}$} & \multicolumn{6}{|c|}{ Existência de banheiro ou sanitário } \\
\hline & & \multicolumn{4}{|c|}{ Com banheiro ou sanitário (destino do esgoto) } & \multicolumn{2}{|c|}{$\begin{array}{c}\text { Sem banheiro ou } \\
\text { sanitário }\end{array}$} \\
\hline & & $\begin{array}{l}\text { Rede ou } \\
\text { fossa }\end{array}$ & $\%$ & Céu aberto & $\%$ & $\mathrm{~N}^{\circ}$ & $\%$ \\
\hline Anchieta & 4.973 & 4700 & 94,50 & 147 & 2,96 & 126 & 2,53 \\
\hline Cachoeiro do Itapemirim & 48.505 & 42.874 & 88,39 & 5.205 & 10,74 & 426 & 0,88 \\
\hline Cariacica & 88.092 & 76.047 & 86,33 & 10.732 & 12,17 & 1.313 & 1,49 \\
\hline Guarapari & 24.535 & 20.843 & 84,95 & 3.326 & 13,56 & 366 & 1,49 \\
\hline Itapemirim & 7.364 & 5.930 & 80,52 & 969 & 13,16 & 465 & 6,31 \\
\hline Marataízes & 8.386 & 7.419 & 88,47 & 529 & 6,30 & 438 & 5,22 \\
\hline Piúma & 4.114 & 3.510 & 85,31 & 539 & 13,10 & 65 & 1,58 \\
\hline Presidente Kennedy & 2.619 & 1.705 & 65,10 & 570 & 21,76 & 344 & 13,13 \\
\hline Viana & 14.190 & 12.271 & 86,48 & 1.675 & 11,81 & 244 & 1,72 \\
\hline Vila Velha & 98.939 & 92.232 & 93,22 & 5.827 & 5,89 & 880 & 0,89 \\
\hline Vitória & 85.558 & 83.881 & 98,04 & 1.040 & 1,21 & 637 & 0,74 \\
\hline \multicolumn{8}{|l|}{ Litoral Sul } \\
\hline ES & & & & & & & \\
\hline
\end{tabular}

FONTE: IBGE. Censo Demográfico, 2000.

Organização: Renata Cometti, 2003.

Presidente Kennedy e Marataízes, os décimos menores índices do Espírito Santo.

Outro conjunto de índices importantes para análise do lugar são os que compõem o Índice de Desenvolvimento Municipal do Espírito Santo (IDM-ES), conforme pode ser visto na Tabela 15.

O município de Vitória lidera todos os índices, exceto o de desenvolvimento econômico e de infra-estrutura para grandes e médios empreendimentos. No primeiro caso, é preciso que se considere o peso da participação da Sammarco Mineradora no município de Anchieta, elevando-o ao maior índice de desenvolvimento econômico, o que não é acompanhado pelos outros índices isoladamente. Nota-se também que esse mesmo fator eleva Anchieta para o segundo maior índice de desenvolvimento municipal, causado pela sobrevalorização da variável econômica.

A análise dessas variáveis nos permite compreender melhor os conjuntos de municípios pelas suas características: 1) municípios cuja história se estrutura na instalação e/ou expansão de atividades urbano-industriais - Vitória, Vila Velha, Cariacica e Cachoeiro de Itapemirim; 2) municípios cuja história se organiza primeiramente nas atividades agropecuárias e que têm atualmente um setor urbano estruturado - Guarapari, Piúma e Anchieta; e 3) municípios com forte vinculação até os dias atuais com a atividade rural, porém de baixa produtividade (no caso da agricultura diversificada) ou monoculturas para suprimento de atividades industriais.

Esse complexo encontra-se atualmente inserido em uma grande dinâmica de transformação a partir de alguns vetores econômicos: o início da exploração de petróleo em plataforma no sul do Estado e a ampliação da extração de granito e mármore em áreas do cristalino próximas (interior do estado), somadas à melhoria de infra-estrutura, principalmente de circulação em direção à capital - recuperação da BR-101 Sul e implantação da Rodovia do Sol.

Antes, porém, de abordar essas dinâmicas, analisaremos o quadro agrário atual, cuja descapitalização e bai- 
TABELA 14 - IDH - ÍNDICE DE DESENVOLVIMENTO HUMANO NOS MUNICÍPIOS DO LITORAL SUL- ES - 2000

\begin{tabular}{|l|c|c|c|c|c|c|c|c|}
\hline Município & $\begin{array}{c}\text { Esperança } \\
\text { de vida ao } \\
\text { nascer } \\
\text { (em anos) }\end{array}$ & $\begin{array}{c}\text { Taxa de } \\
\text { alfabeti- } \\
\text { zação de } \\
\text { adultos (\%) }\end{array}$ & $\begin{array}{c}\text { Taxa bruta } \\
\text { de } \\
\text { freqüência } \\
\text { escolar (\%) }\end{array}$ & $\begin{array}{c}\text { Renda per } \\
\text { capita (em } \\
\text { R\$ de } \\
2000)\end{array}$ & $\begin{array}{c}\text { Índice de } \\
\text { longevi- } \\
\text { dade } \\
\text { (IDHM-L) }\end{array}$ & $\begin{array}{c}\text { Índice de de } \\
\text { educação } \\
\text { (IDHM-E) })\end{array}$ & $\begin{array}{c}\text { Índice de } \\
\text { renda } \\
\text { (IDHM-R) }\end{array}$ & $\begin{array}{c}\text { Índice de } \\
\text { desenv. } \\
\text { humano } \\
\text { municipal } \\
\text { (IDH-M) }\end{array}$ \\
\hline Anchieta & 72,02 & 89,60 & 88,16 & 227,80 & 0,784 & 0,891 & 0,679 & 0,785 \\
\hline Cachoeiro de Itapemirim & 68,92 & 91,11 & 77,85 & 275,62 & 0,732 & 0,867 & 0,711 & 0,770 \\
\hline Cariacica & 67,16 & 91,30 & 80,65 & 215,20 & 0,703 & 0,878 & 0,669 & 0,750 \\
\hline Guarapari & 72,02 & 91,08 & 79,58 & 277,93 & 0,784 & 0,872 & 0,712 & 0,789 \\
\hline Itapemirim & 64,24 & 85,14 & 67,37 & 153,96 & 0,654 & 0,792 & 0,613 & 0,687 \\
\hline Marataízes & 64,24 & 87,37 & 76,80 & 226,36 & 0,654 & 0,839 & 0,678 & 0,723 \\
\hline Piúma & 72,02 & 89,93 & 76,22 & 244,33 & 0,784 & 0,854 & 0,691 & 0,776 \\
\hline Presidente Kennedy & 64,24 & 76,65 & 74,89 & 147,38 & 0,654 & 0,761 & 0,606 & 0,674 \\
\hline Viana & 67,05 & 90,43 & 81,27 & 175,43 & 0,701 & 0,874 & 0,635 & 0,737 \\
\hline Vila Velha & 69,05 & 94,70 & 89,01 & 443,79 & 0,734 & 0,928 & 0,790 & 0,817 \\
\hline Vitória & 70,74 & 95,48 & 93,36 & 667,67 & 0,762 & 0,948 & 0,858 & 0,856 \\
\hline
\end{tabular}

FONTE: PNUD/Ipea (disponível em www.pnud.org, acesso em setembro de 2004).

Organização: Gisele Girardi, 2004.

TABELA 15 - IDM-ES - ÍNDICE DE DESENVOLVIMENTO DOS MUNICÍPIOS DO LITORAL SUL-ES - 2000

\begin{tabular}{|c|c|c|c|c|c|c|c|}
\hline Município & $\mathrm{IDU}^{1}$ & IDS $^{2}$ & $\mathrm{IFM}^{3}$ & $\mathrm{IDE}^{4}$ & IGME $^{5}$ & $\mathrm{IDM}^{\mathrm{E}} \mathrm{S}^{6}$ & \begin{tabular}{|c|} 
Posição \\
no ranking
\end{tabular} \\
\hline Anchieta & 0,3463 & 0,3434 & 0,2176 & 0,7481 & 0,2550 & 0,3821 & $4^{\circ}$ \\
\hline Cachoeiro de Itapemirim & 0,4763 & 0,3820 & 0,1070 & 0,2539 & 0,3271 & 0,3092 & $6^{\circ}$ \\
\hline Cariacica & 0,4136 & 0,3822 & 0 & 0,0810 & 0,6043 & 0,2962 & $8^{\circ}$ \\
\hline Guarapari & 0,4058 & 0,3521 & 0,2075 & 0,1115 & 0,3077 & 0,2769 & $9^{\circ}$ \\
\hline Itapemirim & 0,3177 & 0,2321 & 0,0412 & 0,1626 & 0,1257 & 0,1759 & $33^{\circ}$ \\
\hline Marataízes & 0,3562 & 0,2691 & 0,0121 & 0,0601 & 0,1028 & 0,1601 & $42^{\circ}$ \\
\hline Piúma & 0,3882 & 0,4313 & 0,1290 & 0,0983 & 0,0743 & 0,2242 & $14^{\circ}$ \\
\hline Presidente Kennedy & 0,2539 & 0,2493 & 0.0377 & 0,0761 & 0.0893 & 0,1412 & $55^{\circ}$ \\
\hline Viana & 0,3758 & 0,2932 & 0,1083 & 0,2293 & 0,3764 & 0,2766 & $10^{\circ}$ \\
\hline Vila Velha & 0,5604 & 0,6125 & 0,0673 & 0,1508 & 0,4875 & 0,3757 & $5^{\circ}$ \\
\hline Vitória & 0,8346 & 0,6543 & 0,5694 & 0,7391 & 0,5419 & 0,6679 & $1^{\circ}$ \\
\hline
\end{tabular}

1. Índice de desenvolvimento urbano; 2 . Índice de desenvolvimento social; 3. Índice de finanças municipais; 4. Índice de desenvolvimento econômico; 5. Índice de infra-estrutura para grandes e médios empreendimentos; 6. Índice de desenvolvimento dos municípios do Espírito Santo

FONTE: Ipes. Índice de desenvolvimento dos municípios do ES - 2000 (disponível em www.ipes.es.gov.br, acesso em setembro de 2004).

Organização: Gisele Girardi, 2004.

xa produtividade contribuem para o movimento de especulação imobiliária, principalmente nos municípios mais ao sul do Estado. Alertamos para o fato de termos aglutinado os dados de Marataízes e Itapemirim, pois à época do Censo Agropecuário, principal fonte de informações, o município de Marataízes, que se desmembrou de Itapemirim, ainda não havia sido instalado.
Analisando as Tabelas 16 e 17, observamos que, de um modo geral, todos os municípios do Litoral Sul (com exceção de Vitória, que é $100 \%$ urbano) apresentam entre $50 \%$ e $60 \%$ de estabelecimentos rurais com até 50 hectares. A área ocupada por esses estabelecimentos é variável: 31,77\% em Vila Velha; 45\%, em média, para Piúma e Presidente Kennedy; 60\%, em média, para Anchieta, 
Cachoeiro do Itapemirim, Itapemirim e Viana; e mais de $70 \%$ para Guarapari e Cariacica. Ainda que se considere, nesse item, a diferenciação em relação à área total dos estabelecimentos agropecuários em cada município, a análise dos dados nos permite afirmar que o Litoral Sul tem uma estrutura fundiária centrada nas pequenas propriedades. A ocupação com pastagens, naturais ou plantadas, é proporcionalmente predominante em todos os municípios considerados. A pecuária, predominantemente bovina, de corte e leite, é significativa em Presidente Kennedy, Anchieta, Itapemirim, Piúma, Cariacica e Guarapari. A produção leiteira é destinada a cooperativas de laticínios, principalmente as localizadas em Alfredo Chaves e Cachoeiro do Itapemirim.

Analisando a segunda principal utilização da terra em área, temos: lavouras permanentes em Anchieta (café e banana), Cachoeiro do Itapemirim e Piúma (café), Viana (banana) e Vila Velha (coco e borracha); lavouras temporá- rias em Itapemirim (abacaxi e cana) e em Presidente Kennedy (feijão, cana, milho e mandioca); matas e florestas naturais, em Cariacica e Guarapari. Na Tabela 18 podem ser observados os principais produtos de cultivos temporários e permanentes. Analisando conjuntamente os dados, é possível observar que poucos produtos ocupam áreas significativas, o que implica maior desgaste de nutrientes do solo e também aponta para a potencialização de problemas de assoreamento e contaminação de cursos d'água por utilização de insumos agrícolas, particularmente pesticidas. Esse contexto vai interferir na área costeira do Litoral Sul, que abriga as desembocaduras de 5 das 12 bacias hidrográficas do Espírito Santo: Santa Maria da Vitória, Jucu, Benevente, Itapemirim e Itabapoana.

Retomando a análise do quadro agrário, observamos que os municípios que apresentam maior porcentual de população rural e de pessoal ocupado nas atividades agropecuárias são Itapemirim e Presidente Kennedy, prin-

TABELA 16 - SITUAÇÃO AGRÁRIA: POPULAÇÃO RURAL, ESTABELECIMENTOS AGROPECUÁRIOS, FORÇADE TRABALHO E PARTICIPAÇÃO DO SETOR PRIMÁRIO NO PIB

\begin{tabular}{|c|c|c|c|c|c|c|c|}
\hline \multirow[b]{2}{*}{ Municípios } & \multirow{2}{*}{$\begin{array}{c}\text { \% de } \\
\text { Popula- } \\
\text { ção } \\
\text { rural } \\
(2000)\end{array}$} & \multirow{2}{*}{$\begin{array}{c}\text { Área } \\
\text { ocupada } \\
\text { pelos } \\
\text { estabele- } \\
\text { cimentos } \\
\text { agrope- } \\
\text { cuários } \\
\text { (em ha) }\end{array}$} & \multirow{2}{*}{$\begin{array}{c}\% \text { da área } \\
\text { do } \\
\text { município } \\
\text { ocupada } \\
\text { por } \\
\text { estabele- } \\
\text { cimentos } \\
\text { agrope- } \\
\text { cuários }\end{array}$} & \multicolumn{2}{|c|}{$\begin{array}{c}\% \text { dos estabelecimentos } \\
\text { com até } 50 \text { ha }\end{array}$} & \multirow{2}{*}{$\begin{array}{c}\% \text { de } \\
\text { pessoal } \\
\text { ocupado } \\
\text { em } \\
\text { atividades } \\
\text { agrope- } \\
\text { cuárias }\end{array}$} & \multirow{2}{*}{$\begin{array}{c}\% \text { do } \\
\text { setor } \\
\text { primário } \\
\text { na } \\
\text { compo- } \\
\text { sição do } \\
\text { PIB }\end{array}$} \\
\hline & & & & $\begin{array}{c}\text { Em relação } \\
\text { ao número } \\
\text { total de } \\
\text { estabele- } \\
\text { cimentos }\end{array}$ & $\begin{array}{c}\text { Em relação } \\
\text { à área total } \\
\text { dos } \\
\text { estabele- } \\
\text { cimentos }\end{array}$ & & \\
\hline Anchieta & 31 & $24.147,95$ & 57,92 & 57,61 & 55,42 & 19,8 & 2,85 \\
\hline Cachoeiro do Itapemirim & 11,1 & $62.177,43$ & 70,66 & 56,6 & 61,02 & 7,1 & 2,48 \\
\hline Cariacica & 3,5 & $8.636,40$ & 31,63 & 56,86 & 91,72 & 2,6 & 0,26 \\
\hline Guarapari & 6,6 & $42.481,55$ & 73,20 & 57,27 & 71,82 & 8,5 & 3,33 \\
\hline Itapemirim & 42,6 & $55.671,23$ & 80,81 & 51,62 & 59,03 & 19,8 & 23,32 \\
\hline Piúma & 5,9 & $6.272,09$ & 85,99 & 56,91 & 47,33 & 6,8 & 2,17 \\
\hline Presidente Kennedy & 73,5 & $54.576,87$ & 93,02 & 52,6 & 42,44 & 50,9 & 36,88 \\
\hline Viana & 7,2 & $13.603,16$ & 46,27 & 56,96 & 62,18 & 7,2 & 2,43 \\
\hline Vila Velha & 0,4 & $2.168,04$ & 9,94 & 58 & 31,77 & 1,0 & 0,07 \\
\hline
\end{tabular}

FONTES: IBGE. Censo Demográfico, 2000, e Censo Agropecuário, 1995-1996.

Ipes (www.ipes.es.gov.br, acesso em setembro de 2004).

Organização: Gisele Girardi, 2004. 
TABELA 17 - UTILIZAÇÃO DAS TERRAS NOS ESTABELECIMENTOS AGROPECUÁRIOS 1995-1996

\begin{tabular}{|l|r|r|r|r|r|r|r|r|r|}
\hline \multirow{2}{*}{ Municípios } & \multicolumn{9}{|c|}{ Utilização das terras nos estabelecimentos agropecuários (\%) } \\
& \multicolumn{1}{|c|}{$\begin{array}{c}\text { Lavouras } \\
\text { perma- } \\
\text { nentes }\end{array}$} & $\begin{array}{c}\text { Lavouras } \\
\text { temporá- } \\
\text { rias }\end{array}$ & $\begin{array}{c}\text { Lavouras } \\
\text { temporá- } \\
\text { rias em } \\
\text { descanso }\end{array}$ & $\begin{array}{c}\text { Pasta- } \\
\text { nens } \\
\text { naturais }\end{array}$ & $\begin{array}{c}\text { Pasta- } \\
\text { gens } \\
\text { plantadas }\end{array}$ & $\begin{array}{c}\text { Matas e } \\
\text { florestas } \\
\text { naturais }\end{array}$ & $\begin{array}{c}\text { Matas e } \\
\text { florestas } \\
\text { artificiais }\end{array}$ & $\begin{array}{c}\text { Terras } \\
\text { produti- } \\
\text { vas não } \\
\text { utilizadas }\end{array}$ & $\begin{array}{c}\text { Terras } \\
\text { inaprovei- } \\
\text { táveis }\end{array}$ \\
\hline Anchieta & 15,66 & 2,51 & 0,77 & 12,92 & 47,99 & 12,19 & 0,57 & 1,31 & 6,09 \\
\hline Cachoeiro do Itapemirim & 16,17 & 5,58 & 0,98 & 35,54 & 25,19 & 9,51 & 0,36 & 1,33 & 5,33 \\
\hline Cariacica & 17,29 & 4,81 & 2,98 & 10,78 & 32,78 & 20,17 & 0,14 & 4,9 & 6,15 \\
\hline Guarapari & 16,04 & 1,39 & 2,07 & 5,98 & 37,12 & 23,1 & 0,94 & 5,77 & 7,6 \\
\hline Itapemirim & 2,18 & 37,35 & 2,28 & 27,42 & 17,64 & 5,13 & 0,56 & 3,19 & 4,24 \\
\hline Piúma & 6,07 & 2,67 & 0,53 & 20,21 & 60,47 & 5,54 & 0,55 & 0,81 & 3,17 \\
\hline Presidente Kennedy & 1,92 & 8,26 & 1,19 & 6,19 & 73,78 & 6,1 & 0,34 & 0,42 & 1,8 \\
\hline Viana & 13 & 6,12 & 1,64 & 18,63 & 39,4 & 10,85 & 0,72 & 3,06 & 6,58 \\
\hline Vila Velha & 6,25 & 4,17 & -19 & 5,79 & 73,69 & 5,92 & 0,39 & 1,19 & 2,59 \\
\hline
\end{tabular}

FONTE: IBGE. Censo Agropecuário - Espírito Santo, 1995-1996.

Organização: Gisele Girardi, 2004.

cipalmente vinculadas à produção pecuária e aos cultivos de cana-de-açúcar e abacaxi, e são esses municípios que apresentam o maior porcentual do setor primário no PIB municipal.

São também esses municípios os primeiros a receber royalties da exploração de petróleo off-shore, iniciada em 2002, pois se localizam na área de influência do campo Jubarte (Bacia de Campos).

Os dados contidos na Tabela 19 permitem ter uma referência da significância do recebimento dos royalties de petróleo para os municípios do sul.

\section{À guisa de conclusão: tendências e cenários da ocupação do Litoral Sul do Espírito Santo}

A intensificação da atividade relacionada ao petróleo é, certamente, a de maior impacto no uso e ocupação do solo no Litoral Sul do Espírito Santo. São observadas as consequiências dessa nova modalidade econômica em diferentes âmbitos da vida e da organização do espaço sul-capixaba. Uma delas reside na aplicação da arrecadação de royalties por parte das prefeituras locais. A precariedade das rela- ções sociais tem criado distorções nesta aplicação. A título de exemplo, recentemente foi notificado em jornal de circulação estadual que o município de Presidente Kennedy, a despeito de apresentar precariedade na infra-estrutura urbana e viária e de fazer parte do bolsão de pobreza da bacia do rio Itabapoana, gastou, durante o carnaval, mais de trezentos mil reais em bandas e trios elétricos (JORNAL A GAZETA, 20/02/2005).

Ao se percorrer a Rodovia ES-060, de Marataízes à foz do rio Itabapoana, rodovia que em sua maior parte é próxima à orla, observa-se uma quantidade significativa de loteamentos que vão substituindo áreas de restinga, alguns parcialmente ocupados, outros somente com demarcação de lotes e arruamento básico. Cartazes e placas ao longo da rodovia divulgam a oferta dos terrenos.

Ambos os fatores combinados anunciam um potencial surto especulador e de ocupação com segundas residências. A rapidez do processo alerta para a tendência de reprodução das condições de ocupação que marcaram parte significativa do litoral do Espírito Santo que, em última análise, desdobram-se na deterioração das condições da orla.

Outra tendência que podemos apontar é aquela que vem ocorrendo na área central do município de Marataízes. 
TABELA 18 - CULTIVOS PERMANENTES E TEMPORÁRIOS PRINCIPAIS, EM PORCENTAGEM DE ÁREA OCUPADA, NOS MUNICÍPIOS DO LITORAL SUL-ES - 1995-1996

\begin{tabular}{|c|c|c|c|c|c|c|c|c|c|c|c|c|c|c|}
\hline \multirow{2}{*}{ Municípios } & \multicolumn{8}{|c|}{$\begin{array}{c}\text { \% da área cultivada em relação à área } \\
\text { de lavouras permanentes }\end{array}$} & \multicolumn{6}{|c|}{$\begin{array}{c}\text { \% da área cultivada em relação à } \\
\text { área de lavouras temporárias }\end{array}$} \\
\hline & $\begin{array}{c}\text { Bana- } \\
\text { na }\end{array}$ & $\begin{array}{c}\text { Borra- } \\
\text { cha }\end{array}$ & Café & Coco $\mid$ & Laranja & Manga & $\begin{array}{l}\text { Mara- } \\
\text { cujá }\end{array}$ & $\begin{array}{c}\text { Tange } \\
\text { rina }\end{array}$ & $\begin{array}{c}\text { Abaca } \\
\text { xi }\end{array}$ & & Cana & Feijão & $\begin{array}{c}\text { Mandi- } \\
\text { oca }\end{array}$ & Milho \\
\hline Anchieta & 47,8 & 17,16 & 31,97 & 2,18 & 0,41 & - & - & 0,03 & 8,47 & 8,47 & 5,65 & 37,85 & 533,9 & 5,65 \\
\hline Cachoeiro de Itapemirin & 8,49 & 0,28 & 86,21 & 0,77 & 2,38 & 0,59 & - & 0,29 & - & 3,39 & 20,33 & 314,84 & 47,79 & 51,63 \\
\hline Cariacica & 63,2 & 2,31 & 28,86 & 1,44 & 1,44 & - & - & 0,14 & - & 6,3 & 12,34 & 427,71 & 125,19 & 25,19 \\
\hline Guarapari & 33,79 & 18,95 & 41,26 & 3,61 & 1,47 & 0,24 & - & 0,15 & 0,31 & 1,86 & 4,64 & 25,08 & 81,18 & 26,93 \\
\hline Itapemirim & 31,1 & 9,38 & 48,93 & 6,57 & 2,95 & 0,67 & 0,4 & - & 29,78 & 0,05 & 60,55 & $5,0,1$ & 8,17 & 1,34 \\
\hline Piúma & 9,52 & - & 89,05 & 0,48 & 0,48 & 0,48 & - & - & 3,64 & - & - & - & - & - \\
\hline Presidente Kennedy & 9,02 & - & 74,65 & $\mid 1,56$ & 7,31 & 1,24 & 4,51 & 0,31 & 7,5 & 9,09 & 27,27 & 732,73 & 310,91 & 16,36 \\
\hline Viana & 59,56 & 11,37 & 22,2 & 0,43 & 2,06 & 0,05 & - & 0,49 & - & 1,88 & 30,02 & 2,44 & 45,03 & 13,13 \\
\hline Vila Velha & - & 35,21 & 15,49 & 49,3 & - & - & - & - & - & 2,99 & 17,04 & 26,91 & 129 & 22,42 \\
\hline
\end{tabular}

FONTE: IBGE. Censo Agropecuário - Espírito Santo, 1995-1996.

Organização: Gisele Girardi, 2004.

TABELA 19 - PRINCIPAIS IMPOSTOS ARRECADADOS (2001) E ROYALTIES DO PETRÓLEO (2003) NOS MUNICÍPIOS DO LITORAL SUL-ES, EM R\$

\begin{tabular}{|l|c|c|c|}
\hline \multirow{2}{*}{ Municípios } & \multicolumn{2}{|c|}{ Principais impostos arrecadados } & \multirow{2}{*}{$\begin{array}{c}\text { Royalties da } \\
\text { exploração de } \\
\text { petróleo } \\
2003\end{array}$} \\
\cline { 2 - 3 } & IPVA - 2001 & ICMS - 2001 & $161.799,44$ \\
\hline Anchieta & $172.157,80$ & $2.608 .603,00$ & $52.819,86$ \\
\hline Cachoeiro do Itapemirim & $4.186 .018,59$ & $47.166 .012,00$ & - \\
\hline Cariacica & $3.758 .559,03$ & $60.289 .931,00$ & $47.537,88$ \\
\hline Guarapari & $1.386 .252,09$ & $5.356 .952,00$ & $724.481,68$ \\
\hline Itapemirim & $188.162,24$ & $1.207 .863,00$ & $36.973,90$ \\
\hline Martataízes & $274.007,82$ & $705.655,00$ & $30.371,40$ \\
\hline Piúma & $178.240,22$ & $500.648,00$ & $2.591 .145,41$ \\
\hline Presidente Kennedy & $72.860,79$ & $42.995,00$ & - \\
\hline Viana & $464.957,04$ & $11.598 .865,00$ & - \\
\hline Vila Velha & $8.696 .705,54$ & $213.291 .778,00$ & - \\
\hline Vitória & $14.433 .117,95$ & $1.603 .592 .351,00$ & - \\
\hline
\end{tabular}

FONTES: Finanças municipais, 2002; ANP (disponível em www.anp.gov.br, acesso em setembro de 2004).

Organização: Gisele Girardi, 2004. 
Este balneário, que já foi um importante pólo turístico no litoral sul, tem sofrido intenso processo erosivo na praia, chegando a solapar parte da avenida que beira a orla. A situação alcançou tal gravidade que foram instalados espigões (gabiões) para retenção de sedimentos e recomposição da praia a poucos metros uns dos outros. A ausência de praia e a deterioração paisagística foram responsáveis por uma crise geral no setor turístico do município, particularmente o de sol-e-praia, predominante na área central de Marataízes.

A infra-estrutura já instalada, somada à desvalorização dos patrimônios imobiliários decorrente da deterioração da praia, aponta a tendência de ocupação da área central de Marataízes por atividades direta ou indiretamente voltadas à economia do petróleo, como instalação de empresas e de serviços para atender à demanda de um novo conteúdo social, à semelhança do processo que teve lugar em Macaé, no norte do Rio de Janeiro.

Situação diversa verifica-se mais ao norte, no município de Piúma. Como apontado nas análises das tabelas, Piúma destaca-se na infra-estrutura urbana e tem sediado lançamentos de empreendimentos imobiliários de alto padrão com o propósito de atender a atividade de turismo de veraneio, demandada pela Região Metropolitana, ou a residência da nova classe voltada à economia do petróleo.

Finalmente, destaca-se que, nos municípios da Região Metropolitana, particularmente em Vitória e em Vila Velha, a economia do petróleo está sendo responsável por uma intensa dinamização imobiliária, ampliando o número de lançamentos de novos empreendimentos residenciais, que têm valorizado bairros como Jardim da Penha, Jardim Camburi, Mata da Praia e Praia do Canto (em Vitória) e Praia da Costa, Itapoã e Itaparica (em Vila Velha). O setor turístico em Vitória também tem se intensificado e se especializado na modalidade de turismo de negócios, com significativa instalação de rede hoteleira e de centros de convenções nos últimos anos.

Os desdobramentos dessa dinamização, seja em termos dos fluxos financeiros, que criam demandas para com- plexas redes de serviços, seja em termos demográficos, apontam para a renovação da dinâmica de ocupação do Litoral Sul em moldes semelhantes ao que se desenvolveu à época da instalação das grandes empresas, comentado no início deste artigo. Novas demandas por imóveis de veraneio e de serviços, como, por exemplo, a casa de espetáculos Multiplace Mais, instalada no balneário de Meaípe, em Guarapari, produzem um efeito em cascata que se reflete na valoração e na valorização diferencial dos espaços litorâneos.

Os cenários apresentados vão se consolidando, com maior ou menor velocidade, e sua extrema atualidade não só justifica como demanda conhecimentos pautados na observação constante dos processos naturais e de produção do espaço litorâneo, contribuição certa do desenvolvimento dos estudos do Instituto do Milênio - Recursos Costeiros.

\section{Agradecimentos}

Ao CNPq, pelo financiamento da bolsa de iniciação científica no projeto Instituto do Milênio-RecosMMOC; à equipe do subgrupo temático Uso e Ocupação do Solo do Milênio-Recos-MMOC, pelas ricas contribuições nos Workshops: Amilcar Carvalho Mendes e Luci Cajueiro (PA), Marinez Scherer (SC), Nelson Sambaqui Gruber e Nina Simone Fujimoto (RS), Reiner Olíbano Rosas (RJ), Naina Pierri Estades, Roberto Sampaio e Rodolfo José Angulo (PR), Cláudia Cámara do Vale (ES); aos bolsistas do MMOC-ES, pelas contribuições nas coletas e análises de informações estatísticas e bibliográficas e nos trabalhos de campo: Alexandre Pasolini, Antonio de Oliveira Júnior, Giseli Modolo Vieira Machado, Luiza Leonardi Bricalli e Thiago de Alencar Silva; e aos coordenadores do MMOC, pelos empenho na garantia das condições necessárias para a realização do trabalho: Eduardo Marone (Coordenador geral) e Jacqueline Albino (Coordenadora da Equipe ES). 


\section{Referências}

AlBINO, J.; PAIVA, D. S.; MACHADO, G. M. Geomorfologia, tipologia, vulnerabilidade erosiva e ocupação urbana das praias do litoral do Espírito Santo, Brasil. Geografares, Vitória, n. 2, p. 63-69, 2001.

ALBINO, J.; GIRARDI, G.; NASCIMENTO, K. A. Erosão e progradação costeira do litoral do Espírito Santo. In: MUHE, D. (Org.). Atlas de erosão e progradação costeira do litoral brasileiro. (no prelo)

ARAÚJO FILHO, J. R. O porto de Vitória. São Paulo: IgeogUSP, 1974. 316 p. (Série Teses e Monografias, 9)

BECKER, B. O norte do Espírito Santo: região periférica em transformação. Revista Brasileira de Geografia, Rio de Janeiro, v. 4, n. 35, p. 35-112, 1973.

BORGO, I. A. L.; ROSA, L. B. R. A.; PACHECO, R. J. C. Norte do Espírito Santo: ciclo madeireiro e povoamento (18101960). Vitória: Edufes, 1996.178 p.

BOUDOU, J.-L. Em favor da talassografia. Geografares, Vitória, n. 2, p. 71-80, 2001.

BRASIL. Plano nacional de gerenciamento costeiro. Disponível em: <http://www.mma.gov.br>.

CAMPOS JÚNIOR, C. T. O novo arrabalde. Vitória: P.M.V./ Secretaria Municipal de Cultura e Turismo, 1996. 250 p.

CECOPES. Grandes projetos industriais no Espírito Santo. Vitória, [198-]. 32 p.

DEMONER, S. M. Como foram povoadas as terras capixabas. Revista do IJSN, Vitória, v. 3, n. 5, p. 28-29, 1986.

FINDES/IEL/IDEIES. 150 maiores empresas - Espírito Santo. Vitória: Mídia Certa, 1999. 138 p.
GAZETA Mercantil. Atlas - Espírito Santo. Rio de Janeiro, 2000. 114 p.

GAZETA Mercantil. Balanço anual - Espírito Santo. Rio de Janeiro, 2000. 90 p.

IBGE - INSTITUTO BRASILEIRO DE GEOGRAFIA E ES-

TATÍSTICA. Censo demográfico. Disponível em: <http:// www.ibge.gov.br>. Acesso em: 2000.

IPES - INSTITUTO DE PESQUISA DO ESPÍRITO SANTO. Perfil dos municípios do Espírito Santo. Disponível em: <http:/ /www.ipes.es.gov.br>. Acesso em: 2000.

MARTIN, L. et al. Geologia do quaternário costeiro do litoral norte do Rio de Janeiro e do Espírito Santo. São Paulo: CPRM/Fapesp, 1997. 112 p.

MORAES, A. C. R. Contribuição para a gestão da zona costeira no Brasil: elementos para uma geografia do litoral brasileiro. São Paulo: Hucitec/Edusp, 1999. 229 p.

PETRONE, P. Aspectos geográficos da área de colonização antiga do Estado do Espírito Santo. São Paulo: AGB, 1962. 112 p. (Avulso 3)

SAINT-HILAIRE, A. Viagem ao Espírito Santo e Rio Doce. São Paulo: Itatiaia/Edusp, 1974. 122 p. (Coleção Reconquista do Brasil, 6)

SALETTO, N. Transição para o trabalho livre e pequena propriedade no Espírito Santo (1988-1930). Vitória: Edufes, 1996. $162 \mathrm{p}$.

SANTOS, M. A natureza do espaço: técnica e tempo, razão e emoção. 2. ed. São Paulo: Hucitec, 1997. 308 p. 